\title{
Capturing the Transport Variability of a Western Boundary Jet: Results from the Agulhas Current Time-Series Experiment (ACT)*
}

\author{
Lisa M. Beal, Shane Elipot, Adam Houk, And Greta M. Leber \\ Rosenstiel School of Marine and Atmospheric Science, University of Miami, Miami, Florida
}

(Manuscript received 20 June 2014, in final form 17 February 2015)

\begin{abstract}
The volume transport of the Agulhas Current was measured over a 3-yr period by an array of seven current meter moorings and four current- and pressure-recording inverted echo sounders (CPIES) deployed at $34^{\circ} \mathrm{S}$. CPIES extended the array farther offshore in order to capture, for the first time, the full Agulhas Current during meander events. Transports derived from CPIES are well correlated with overlapping current meter transports (0.89). The Eulerian mean current is $219 \mathrm{~km}$ wide and $3000 \mathrm{~m}$ deep, with peak surface speeds of $1.8 \mathrm{~m} \mathrm{~s}^{-1}$ and a weak northward undercurrent on the continental slope below $1200 \mathrm{~m}$. A new algorithm to capture the western boundary jet transport at each time step $T$ is defined as the poleward transport out to the first maximum of the vertically integrated velocity beyond the half-width of the mean jet. The mean transport of the Agulhas Current jet, so defined, is -84 Sverdrups $\left(\mathrm{Sv} ; 1 \mathrm{~Sv} \equiv 10^{6} \mathrm{~m}^{3} \mathrm{~s}^{-1}\right.$ ) with a standard error of $2 \mathrm{~Sv}$. Sampling and instrumental errors are explicitly estimated and amount to an additional $9 \mathrm{~Sv}$. A more traditional estimate, based on net transport integrated to a fixed distance offshore $T_{\text {box }}$, gives a mean transport of $-77 \pm 5 \mathrm{~Sv}$. This transport is $10 \mathrm{~Sv}$ greater than an equivalent transport at $32^{\circ} \mathrm{S}$, corresponding to a latitudinal increase equal to that predicted by Sverdrup dynamics. The time series of $T$ and $T_{\text {box }}$ show important differences during solitary meander events and at longer time scales. In terms of an annual cycle, the Agulhas Current appears strongest during austral summer, a similar phase to the Gulf Stream and Kuroshio.
\end{abstract}

\section{Introduction}

The Agulhas Current is the western boundary current of the south Indian Ocean subtropical gyre. Its variability has been linked upstream to the Indonesian Throughflow and Pacific El Niño-Southern Oscillation (De Ruijter et al. 2005; Le Bars et al. 2013; Putrasahan et al. 2014, manuscript submitted to J. Climate), while downstream it feeds an interocean transport—or "leakage"—of warm and saline waters into the South Atlantic (Gordon 1986). This Agulhas leakage is thought to stabilize the Atlantic meridional overturning circulation (AMOC) (Weijer et al. 2002; Peeters et al. 2004) by providing a salt-advection

\footnotetext{
* Supplemental information related to this paper is available at the Journals Online website: http://dx.doi.org/10.1175/JPO-D-140119.s1.

Corresponding author address: Lisa M. Beal, RSMAS, University of Miami, 4600 Rickenbacker Causeway, Miami, FL 33149.

E-mail: lbeal@rsmas.miami.edu
}

feedback (Rahmstorf 1996; Beal et al. 2011). There is also evidence that the Agulhas system is a "hotspot" for eddy heat transport into the Southern Ocean (Gille 2003). Regionally, the warm waters of the Agulhas Current influence rainfall and climate over the African continent (Jury et al. 1993; Reason 2001; Rouault et al. 2002), and its periodic separation from the shelf during meander events is thought to drive upwelling and productivity over the eastern Agulhas Bank-a fishery of economic importance to South Africa (Gill and Schumann 1979; Barlow et al. 2010; Krug et al. 2014).

Evidence has been building that the Agulhas Current, its leakage, or both, may be warming and strengthening in response to anthropogenic climate change, with possible consequences for South Atlantic freshwater transport and the AMOC on decadal to centennial time scales (Biastoch et al. 2009; Rouault et al. 2009; Beal et al. 2011; Biastoch and Böning 2013). However, most studies of the Agulhas system are based on modeling, theory, and satellite data. It is important that we establish in situ measurements of the strength and variability of the Agulhas Current so that its 
(a)

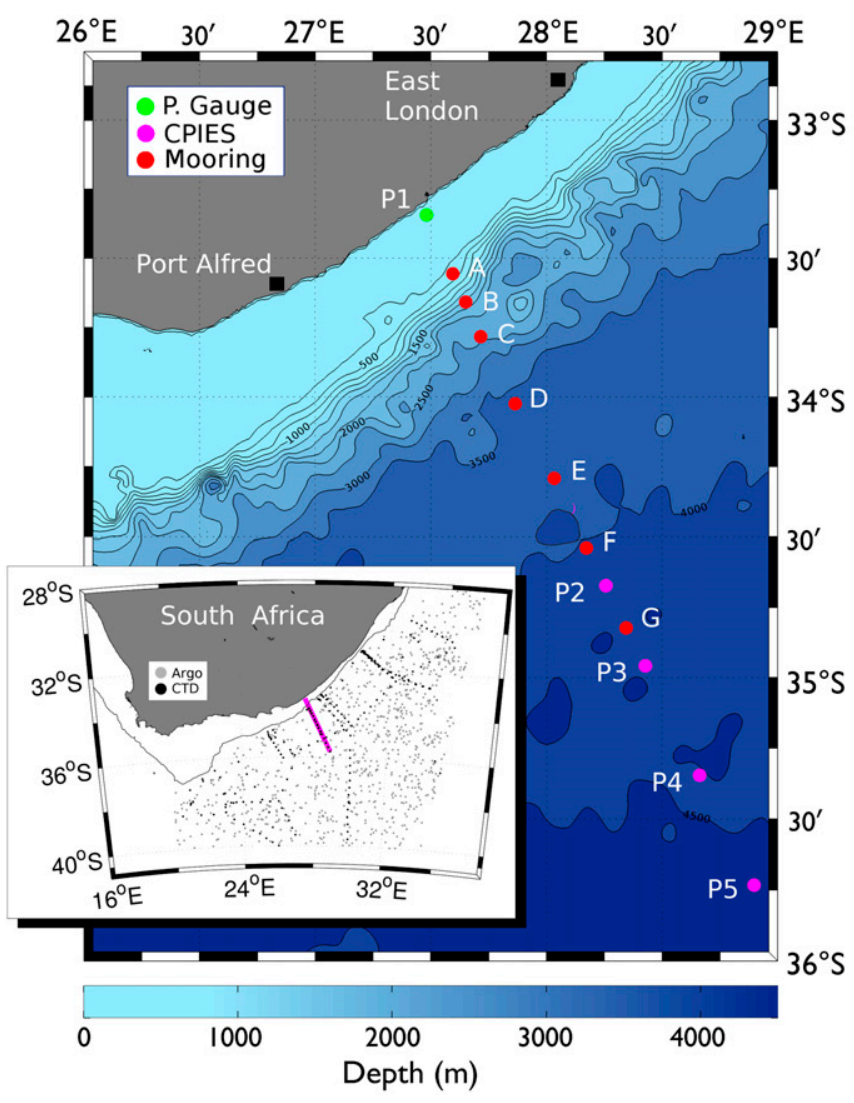

(b)


FIG. 1. (a) Geographical location of the ACT array. Full-depth current meter moorings are in red (A-G), CPIES are in magenta (P2$\mathrm{P} 5)$, and a coastal tide gauge is in green (P1). The African continent is shaded gray, and bathymetry is shown in shades of blue, with contours every $250 \mathrm{~m}$ down to $2000 \mathrm{~m}$ and every $500 \mathrm{~m}$ thereafter. Inset map shows a larger region with the ACT line in magenta plus locations of temperature-salinity profiles from CTD in black and from Argo in gray. (b) Vertical cross sections of the ACT array during the (top) first and (bottom) second deployment periods. ADCPs are shown in red and green at the top of each long mooring and singlepoint Doppler current meters are shown in blue. Bathymetry of the continental slope is shaded black. Instruments circled in red yielded no data return, while those circled in orange yielded partial records.

dynamics can be better understood, simulations can be validated, and natural variability and anthropogenic change can be identified and separated.

Here, we report on first results from the Agulhas Current Time-Series Experiment (ACT), which aims to build a 20-yr proxy for Agulhas transport variability by combining $3 \mathrm{yr}$ of in situ mooring array data with two decades of along-track sea surface height data from satellite altimeter. The ACT array crosses the Agulhas Current off the southeast coast of South Africa close to $34^{\circ} \mathrm{S}$, along an altimeter ground track (Fig. 1). This position is about $400 \mathrm{~km}$ downstream from the historical $32^{\circ} \mathrm{S}$ section, where a 267 -day time series of the current was collected from a five mooring array during the World Ocean Circulation Experiment (WOCE) in 1995 (Bryden et al. 2005). A more southerly latitude was advantageous for ACT because the altimeter ground track is more closely perpendicular to the current path farther south and because the continental shelf is twice as wide, mitigating coastal data quality issues as the altimeter track crosses from land to sea (Vignudelli et al. 2011).

At $32^{\circ} \mathrm{S}$, Bryden et al. (2005) found that the mean and standard deviation in transport of the Agulhas Current is $-70 \pm 22$ Sverdrups $\left(\mathrm{Sv} ; 1 \mathrm{~Sv} \equiv 10^{6} \mathrm{~m}^{3} \mathrm{~s}^{-1}\right)$, making it the strongest western boundary current in the world based on comparisons with time series in the Kuroshio and Gulf Stream at similar latitudes. The extraordinary strength of the Agulhas is largely related to the addition of about $15 \mathrm{~Sv}$ to the south Indian Ocean subtropical gyre from the Pacific via the Indonesian Throughflow (Gordon et al. 2010; Lee et al. 2010). Bryden et al. (2005) found maximum along-stream variance of the Agulhas Current at time scales of 50-70 days, corresponding to the propagation of solitary meanders across the mooring 
array. These meanders, previously referred to as Natal pulses because of their frequent detection off the Natal Bight (Lutjeharms and Roberts 1988), result in detachment of the current from the continental slope and the formation of an inshore cyclone about $100 \mathrm{~km}$ in diameter. They typically advect downstream at about $15 \mathrm{~km} \mathrm{day}^{-1}$ and into the retroflection region, where they are thought to lead to Agulhas ring shedding (Schouten et al. 2002; van Leeuwen et al. 2000).

Oceanographers have been addressing the question of seasonality of the Agulhas Current for decades (Pearce and Grundlingh 1982), but a conclusion has remained elusive, owing to the lack of long-term measurements. Ocean models have predicted an annual cycle with weaker transports in austral summer-fall (FebruaryMarch) and strongest transports in austral winter-spring (Matano et al. 2002; Biastoch et al. 1999). These simulations suggested that tropical winds, through their influence on the flow of waters into the Agulhas Current via the Mozambique Channel, dominate the seasonal signal at the western boundary, which is blocked from the subtropical interior by the Mozambique Ridge. The observed seasonal signal farther north in the Mozambique Channel matches the phase in these models. It is strongest (southward) in austral winter-spring and has been explained by phase-lagged subtropical wind stress curl to the east of Madagascar and the island rule (Ridderinkhof et al. 2010). However, along-track satellite sea surface heights across the Agulhas Current suggest maximum surface geostrophic currents in austral summer (Krug and Tournadre 2012), nearly opposite the cycle found in numerical simulations and in the Mozambique Channel.

Even less is known about the interannual to decadal variability of the Agulhas system. Mesoscale anomalies in the system, including meanders and Agulhas rings, are thought to have interannual variability linked to the Indian Ocean dipole and El Niño-Southern Oscillation modes (Schouten et al. 2002; De Ruijter et al. 2005; Ridderinkhof et al. 2010; Putrasahan et al. 2014, manuscript submitted to J. Climate). But it is not clear whether these anomalies, as measured by eddy kinetic energy or sea surface temperature, can be related to the transports of the Agulhas Current or its leakage (Loveday et al. 2014).

In this paper, we describe the ACT experiment and data and use the mooring array measurements to construct an in situ time series of transport for the Agulhas Current at $34^{\circ} \mathrm{S}$. The linear ACT array consists of seven full-depth current meter moorings out to $187 \mathrm{~km}$ offshore and is extended out to $300 \mathrm{~km}$ offshore with an additional four current- and pressure-recording inverted echo sounders from which we derive geostrophic velocities. With this array, for the first time, we are able to capture the full Agulhas Current jet at all times, including during offshore meander events, allowing for a definition of transport based on the velocity field, rather than on geography. This is of particular importance for comparison of our measurements with models, since the jet can be defined identically in the model, regardless of the model resolution and resultant jet width. In addition, we show how the variability of the velocity field relates to transport and estimate an annual cycle for the Agulhas Current.

\section{Measurements and methods}

The ACT array (Fig. 1) was sustained for 34 months, from April 2010 to February 2013. The initial deployment cruise was in 2010 aboard R/V Knorr out of Cape Town (ACT0410). Current meter moorings were subsequently recovered and redeployed in November 2011 aboard R/V Melville (ACT1111). Final recovery of the whole array was in February 2013, once again aboard R/V Knorr (ACT0213). During each cruise, 20 conductivity-temperature-depth-oxygen and lowered acoustic Doppler current profiler $\left(\mathrm{CTDO}_{2}-\mathrm{LADCP}\right)$ stations were occupied along the ACT line, once at night between mooring operations and again as a continuous 3-day transect. In addition, shipboard ADCP measurements were collected continuously, both underway and on station. These one-time data are described in another manuscript (Leber and Beal 2014). For this study, we concentrate on the mooring array results.

\section{a. Array design and instrumentation}

The ACT array consisted of 39 instruments deployed at 12 sites located along TOPEX/Poseidon and Jason-1/2 ground track 96, crossing the Agulhas Current at nominally $34^{\circ} \mathrm{S}$ (Fig. 1). The array orientation is $15^{\circ}$ clockwise of perpendicular with the continental slope. Sites A through $\mathrm{G}$ are full-depth current meter moorings (CMs), with average horizontal spacing of $26 \mathrm{~km}$, and sites $\mathrm{P} 2$ through P5 are current- and pressure-recording inverted echo sounders (CPIES; University of Rhode Island) spaced about $50 \mathrm{~km}$ apart (Table 1). Instrumentation on each CM consists of an upward-looking acoustic Doppler current profiler (ADCP; Teledyne-RD Instruments) profiling the water column to the near surface, plus up to five single-point acoustic Doppler current meters (ADCMs; Nortek Aquadopp) distributed below, with the deepest at $3000 \mathrm{~m}$. The detailed design diagram for mooring $\mathrm{F}$ is shown in Fig. 2 as an example. All current meters measure pressure and temperature in addition to velocity (speed and direction). CPIES are bottommounted with an Aanderaa ZPulse ADCM tethered 
TABLE 1. ACT array mooring positions and depths.

\begin{tabular}{lccc}
\hline \hline Description & Name & $\begin{array}{c}\text { Distance } \\
\text { offshore }(\mathrm{km})\end{array}$ & $\begin{array}{c}\text { Water } \\
\text { depth }(\mathrm{m})\end{array}$ \\
\hline Tide gauge & P1 & 4 & 60 \\
CM & A & 30 & 320 \\
CM & B & 43 & 1260 \\
CM & C & 58 & 2210 \\
CM & D & 88 & 3607 \\
CM & E & 121 & 3701 \\
CM & F & 151 & 3994 \\
CPIES & P2 & 168 & 4248 \\
CM & G & 186 & 4276 \\
CPIES & P3 & 203 & 4374 \\
CPIES & P4 & 251 & 4438 \\
CPIES & P5 & 298 & 4563 \\
\hline
\end{tabular}

$50 \mathrm{~m}$ above the seabed. Of the four CPIES, P2 was placed between $\mathrm{CMs} F$ and $\mathrm{G}$ to allow for comparison of the CPIES-derived transports with those measured directly from velocity, while the remaining three extend the array out to $300 \mathrm{~km}$ offshore (Fig. 1).

There are a few differences in the array design and data recovery between the first and second deployments. During the first deployment, all CMs were topped with 150-kHz ADCPs, positioned $300 \mathrm{~m}$ below the surface (Fig. 1b). On CMs C and D, these ADCPs broke loose after 6 and 16 months, respectively. Fortuitously, they and their data were recovered a couple of days later by the research ship (RS) Africana; however, the ADCM at $500 \mathrm{~m}$ on mooring $\mathrm{C}$ was completely lost. The array design was modified for the second deployment, so that moorings B, C, and $\mathrm{D}$, which experience the strongest velocities, were topped with $75-\mathrm{kHz}$ ADCPs positioned $600 \mathrm{~m}$ below the surface (Fig. 1b, lower panel). There were no breaks or losses during the second deployment, although two instrument failures and a configuration error resulted in missing data below $1500 \mathrm{~m}$ at mooring $\mathrm{E}$ and at $1500 \mathrm{~m}$ on G. CPIES P2-P5 remained in the water throughout the $3 \mathrm{yr}$ of the experiment and were recovered successfully, all providing continuous records over both deployments. In summary, we successfully recovered $95 \%$ of the instrumentation over the course of the experiment: three ADCM records are completely missing and two of the upper-ocean ADCP records are partial (red and orange circles, respectively, in Fig. 1b). In the next two sections, we explain how the CM and CPIES data are collected and processed.

\section{b. Current meter data}

ADCPs were configured to burst sample every hour and ADCMs every $20 \mathrm{~min}$. All velocity records are corrected for sound speed and mapped to a time-varying water depth using measured pressure and temperature

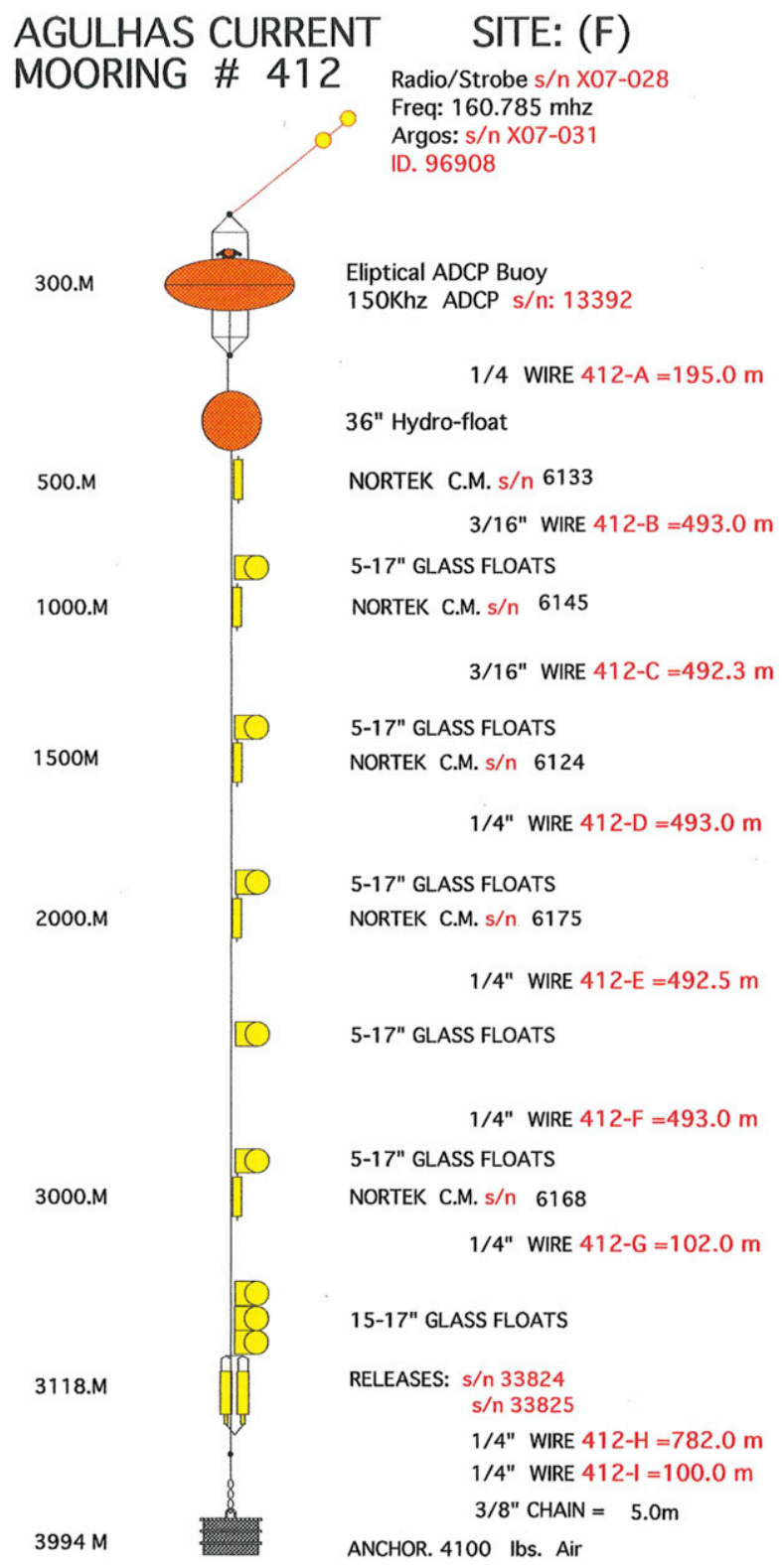

FIG. 2. Design diagram for mooring F (same configuration in both deployments), illustrating the distribution of instrumentation and flotation. Radio, strobe, and Argos beacons are mounted on the top elliptical ADCP buoy, although not explicitly drawn. Numbers on the left are water depth.

(assuming salinity $=35$ ). For ADCPs, data bins within $6 \%$ of the instrument depth from the ocean surface are removed because of side-lobe interference. ADCM data are then averaged to a sampling interval of $1 \mathrm{~h}$, to match ADCP data, and tides and inertial oscillations are removed on all records with a 40-h low-pass filter.

For the second deployment, an update bug in the Nortek deployment planning software meant that blanking distance was misconfigured by almost an order of magnitude 

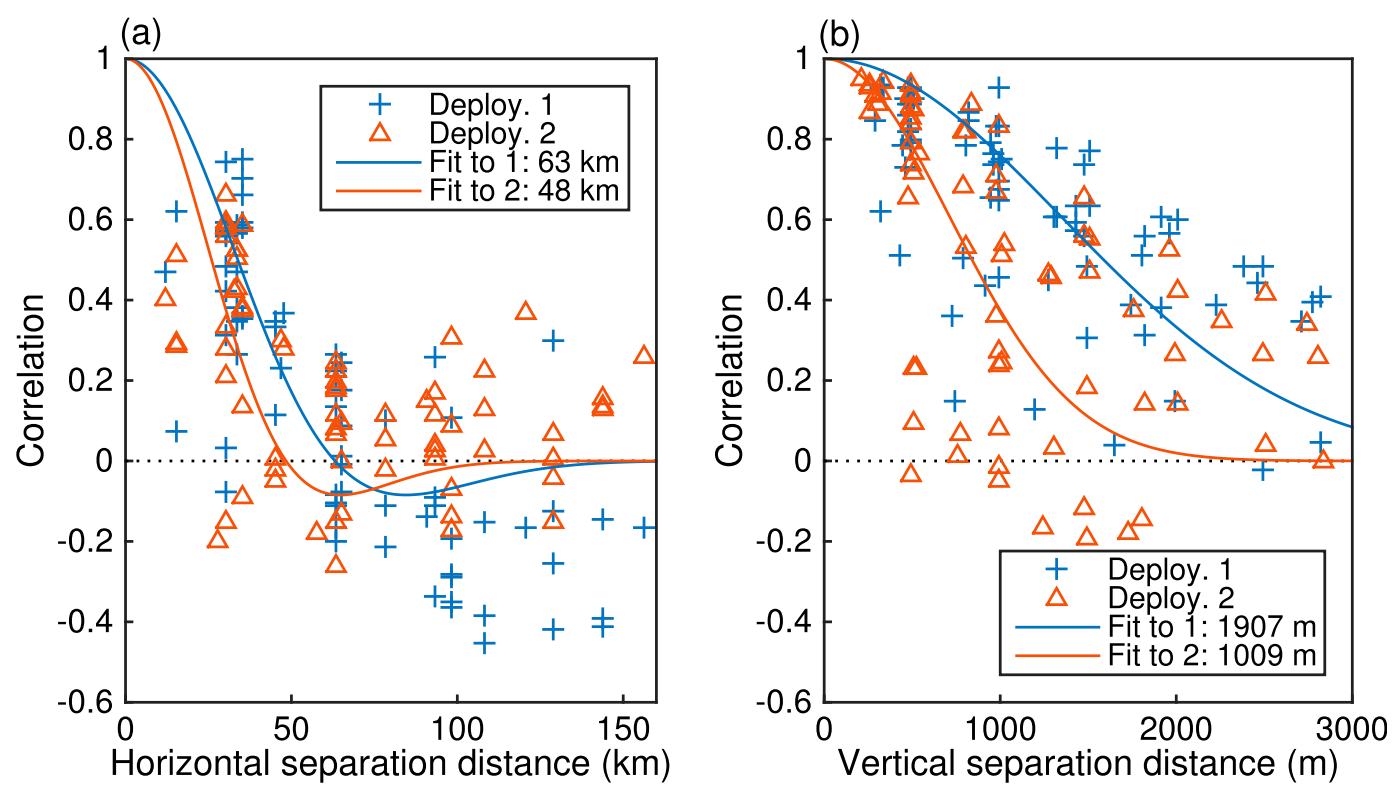

FIG. 3. Cross correlations of pairs of current meter records in (a) the horizontal and (b) vertical, as a function of their separation distance. For the horizontal, pairs of current meters within a spread of $150 \mathrm{~m}$ in the vertical are used. Length scales are obtained from the fit to Eqs. (A1) and (A2), based on the unconstrained nonlinear minimization method (Nelder and Mead 1965).

on all ADCMs. To evaluate the effect on instrumental error, we looked for the background white noise level of each individual velocity spectra. Fortunately the effect is relatively small, with median instrumental errors of $0.7 \mathrm{~cm} \mathrm{~s}^{-1}$ during the first deployment and $0.9 \mathrm{~cm} \mathrm{~s}^{-1}$ during the second.

The ability of the configuration and density of the $\mathrm{CM}$ array to resolve the observed flows can be assessed by evaluating the vertical and horizontal decorrelation length scales of the velocity field and comparing those to the instrument spacing (Fig. 3). We fit covariance functions [Eqs. (A1) and (A2)] to the correlations between pairs of (40-h low passed) velocity records as a function of their separation distance. We find the horizontal scale of the flow is $56 \mathrm{~km}$, about twice the average separation of the CM sites, and the vertical scale is $1500 \mathrm{~m}$. These scales are somewhat different between deployments (Fig. 3), which we attribute to both the difference in the instrumental error, explained above, and in the nature of the variability, which we show later. Both the instrumental error and covariance functions calculated here are used in the appendix to evaluate a transport error from the CM array.

Next, all the filtered instrumental records are combined into vertical profiles with $20-\mathrm{m}$ depth cells. An Akima spline is used to interpolate a smooth profile. To extrapolate to the surface, an average distance of $90 \mathrm{~m}$, we assume a constant shear, taken over the top $50 \mathrm{~m}$ of ADCP data. The error associated with this surface extrapolation can be estimated using the available LADCP measurements over this depth (Fig. 9) and averages to $0.9 \mathrm{~Sv}$ across the whole array. To extrapolate to the seabed we use constant shear, as measured between the two deepest ADCMs, or constant velocity where the deepest ADCM is more than $500 \mathrm{~m}$ above the bottom. At $F$ and $G$, we interpolate to near-bottom records constructed by averaging the velocity data from pairs of CPIES. These additional deep data are particularly valuable during the second deployment because of the increased noise associated with the configuration error. Several of the ADCP records have four or five short temporal gaps (maximum $9 \mathrm{~h}$ ), which are filled linearly in time. The long gaps at the top of moorings C and D during the first deployment are filled by exploiting the strong linear relationship with the records immediately below ( $>0.85$; Fig. 3 ) and then constant shear extrapolation to the surface, as before. During the second deployment, the gap below $1500 \mathrm{~m}$ on mooring $\mathrm{E}$ is filled by using a regression with the $3000-\mathrm{m}$ records from $\mathrm{D}$ and $\mathrm{F}$ on either side. Finally, all profile data are resampled to 12-h time steps and rotated to give crosstrack and along-track velocity components.

\section{c. CPIES data}

CPIES pairs $\mathrm{P} 3-\mathrm{P} 4$ and $\mathrm{P} 4-\mathrm{P} 5$ are used to estimate velocity beyond the end of the CM array (at 227 and $274 \mathrm{~km}$ offshore) so that the transport of the Agulhas Current is fully captured during meander events. We 
validate these estimates by comparing overlapping geostrophic transport from pair P2-P3 with direct transport from mooring G (Fig. 5).

\section{1) PRINCIPLE}

CPIES measure three quantities: acoustic round-trip travel time from the seafloor to the ocean surface, bottom pressure, and near-bottom velocity. From these data, the derivation of full water column geostrophic velocities using pairs of CPIES involves many steps (Donohue et al. 2010), but the principle is relatively simple. Hydrographic data in the vicinity of the study region are used to generate a lookup table of specific volume anomaly profiles $\left[\xi=\sigma_{S, T, p}-\sigma_{35,0, p}\right.$, where $\sigma=1 / \rho$, and $\rho(S, T, p)$ is density] as a function of acoustic round-trip travel time $\tau$. This is called the gravest empirical mode (GEM) field (Meinen and Watts 2000) and allows for the generation of time series of specific volume anomaly profiles from CPIES acoustic round-trip travel time. The CPIES pressure record is used to remove the contribution of mass loading from measured $\tau$. Specific volume anomalies are then integrated over pressure intervals to give time series of geopotential anomaly profiles $\left(\Delta \Phi=\int \xi d p\right)$ at the location of each CPIES. Finally, geostrophic velocities are obtained from the difference of the geopotential anomaly profiles at two adjacent CPIES, referenced to their averaged nearbottom velocity records.

\section{2) Processing}

We derive geostrophic velocity profiles from the CPIES data following the principles outlined above (Kennelly et al. 2007; Donohue et al. 2010). All inverted echo sounders (IES) were configured to emit $2412-\mathrm{kHz}$ pings per hour in bursts of 4 pings every $10 \mathrm{~min}$, from which hourly values were obtained after a noise reduction procedure. Near-bottom velocity and bottom pressure were sampled every $20 \mathrm{~min}$, the former by burst sampling, and also averaged hourly. An alternative method was devised for detiding and dedrifting of pressure records because there was concern that the standard exponential linear drift model of Watts and Kontoyiannis (1990) could mistake real variability for instrumental drift, especially at the beginning of the records. The pressure records were detided by least squares fitting to 97 tidal constituents $(28.0066 \mathrm{~h}$ and shorter) but still exhibited strongly coherent variability, likely ascribable to a fast barotropic oceanic response to large-scale atmospheric forcing. This "common mode" was calculated as the average of all records at each time step and then subtracted from each individual record. A simple linear drift was subsequently subtracted from each record before adding back the common mode. We compared our linear drift
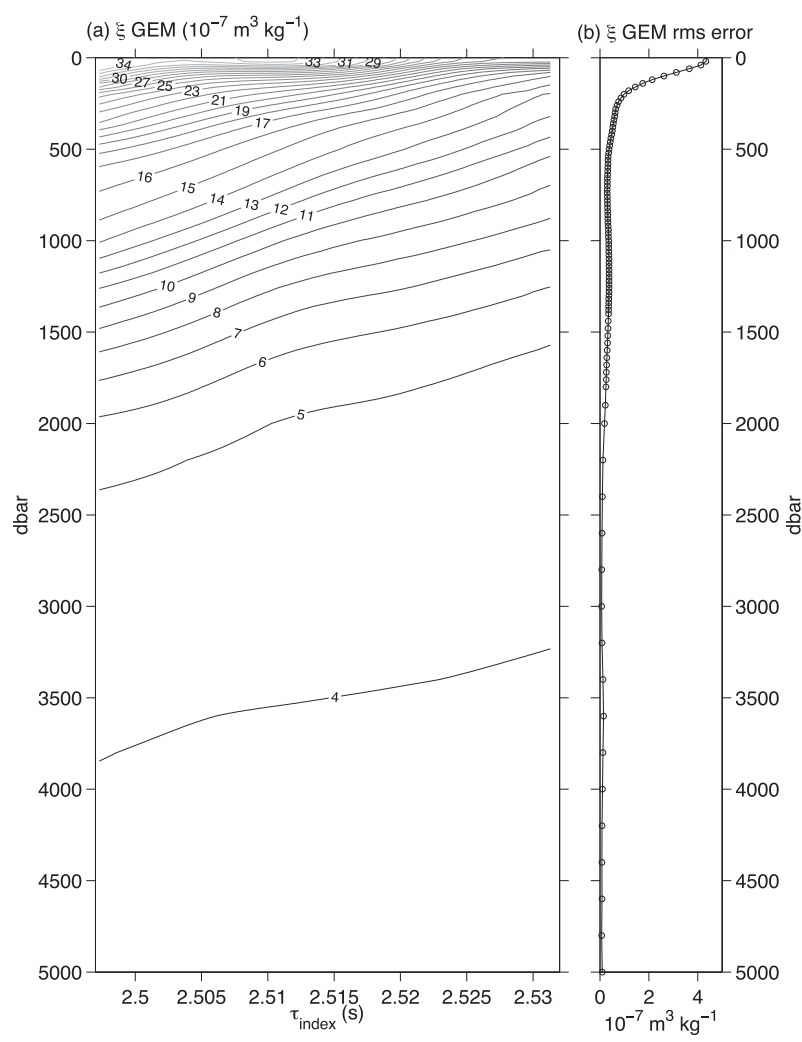

FIG. 4. (a) Gravest empirical mode (GEM) of specific volume anomaly $\xi$ for the ACT region as a function of pressure level and acoustic round-trip travel time index (travel time referenced to $1900 \mathrm{db}$ ). (b) RMS difference across all travel times and as function of pressure level between the $\xi$ GEM field and all $\xi$ values obtained from the hydrographic database. The circles on the curve indicate the pressure levels used to build the GEM field.

estimates to Watts and Kontoyiannis (1990) exponential linear drifts to find an estimated uncertainty in the dedrifting procedure of 1 mbar.

To build the GEM we selected hydrographic profiles between $28^{\circ}$ and $40^{\circ} \mathrm{S}$ and between $21^{\circ}$ and $37^{\circ} \mathrm{E}$, excluding data within the Mozambique basin, as shown in the inset map of Fig. 1. We used 149 CTD profiles from the World Ocean Database, accessed through the National Oceanography Data Center (www.nodc.noaa. gov); 120 CTD profiles from the three ACT cruises; 71 CTD profiles from the Agulhas Undercurrent Experiment in 2004 (Beal et al. 2006); and a further 879 profiles from the Argo database (www.argodatamgt. org). The GEM field was calculated using the procedure described in Donohue et al. (2010) and is shown in Fig. 4. Round-trip travel time $\tau_{\text {index }}$ is referenced to $1900 \mathrm{db}$ in order to utilize the Argo profiles, which are typically no deeper than $2000 \mathrm{db}$. The RMS error of the GEM is a maximum at the surface and decays with 
depth (Fig. 4b), reflecting that significant variance in density (and hence $\xi$ ) over the upper $200 \mathrm{~m}$ is not captured by $\tau_{\text {index }}$.

\section{3) VAlidation: Velocity}

We assess the skill of the CPIES for estimating velocity and transport in the Agulhas Current by comparing velocities derived from pair P2-P3 (which bracket mooring G; Fig. 1) with direct velocities from mooring G. Our comparison is conducted on 40-h low-pass records subsampled at 20 -h intervals. The P2-P3 velocity profiles were interpolated onto the time-varying depths of the ADCP and ADCM data for a direct comparison with each current meter record (Fig. 5).

We find that record-length mean velocities from the $\mathrm{CM}$ and CPIES agree within error bars (Figs. 5a,b), except near $1500 \mathrm{~m}$ for the first deployment and near $2000 \mathrm{~m}$ for both deployments. Error bars represent the standard error of the mean, with the number of degrees of freedom calculated by dividing the length of each time series by its decorrelation time scale. The bias of the CPIES, taken as the difference of the means, is also largest at 1500 and $2000 \mathrm{~m}$, where it is about $2 \mathrm{~cm} \mathrm{~s}^{-1}$. Bias is everywhere positive, except at $3000-\mathrm{m}$ depth during the second deployment. The source of this apparent positive bias is unknown. It could conceivably be related to a mean geostrophic departure of the flow as it accelerates around the concave African coastline. However, a cyclostrophic component would be a maximum at the surface, rather than middepth, and is not evident in LADCP data (Beal and Bryden 1999; Leber and Beal 2014). Furthermore, based on a radius of curvature of $500 \mathrm{~km}$ (Fig. 1), it would average less than $1 \mathrm{~cm} \mathrm{~s}^{-1}$ at $\mathrm{G}$, which is at the mean edge of the Agulhas jet (Fig. 7). More likely it is related to instrumental or sampling errors. For instance, a bias may be introduced by noise in the ADCM measurements, which is greatest at middepth. This has been seen previously and attributed to the minimum in scatterers at that depth (Hogg and Frye 2007). The standard deviations of the CM and CPIES data agree very well, and the correlations between each time series are higher than 0.75 , except below $2000 \mathrm{~m}$ for the second deployment (Figs. 5d,f).

We estimate a total (observed) error as the root-meansquare (RMS) difference between the CPIES and CM time series (Fig. 5e). This constitutes an error that includes the biases seen in Fig. 5c. The error is a maximum of $10 \mathrm{~cm} \mathrm{~s}^{-1}$ below the Ekman layer and decays to about

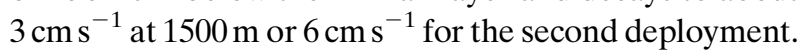
These observed RMS errors are compared to the theoretically estimated CPIES errors calculated from first principles in the appendix. The theoretical errors overestimate observed error by a factor of 2 in the upper water column but are similar in deep waters.

\section{4) VALIDATION: TRANSPORT}

Next, we compare the transport time series estimated for CPIES pair P2-P3 with the overlapping transports from mooring $\mathrm{G}$ (Fig. 6). For this comparison, the velocity profile on mooring $\mathrm{G}$ is constructed as above, except we do not incorporate the averaged P2-P3 ADCM data as a near-bottom record, in order to maintain independence between the two transport estimates. Transport at mooring $\mathrm{G}$ is then calculated by multiplying the velocity profile at each time step by the cross-sectional area, delineated horizontally by the positions of CPIES P2 and $\mathrm{P} 3$ on either side. Geostrophic transport from CPIES pair P2-P3 is calculated similarly, with geostrophic velocity below their deepest common level (so-called bottom triangle) also provided by the GEM, which is defined down to $5000 \mathrm{db}$ (Fig. 4).

The CPIES and CM time series are highly correlated (0.87) and have similar standard deviations (Table 2). Their RMS difference is $7.1 \mathrm{~Sv}$, about $30 \%$ less than the CPIES error estimated from first principles (see the appendix). There is also a CM error of $3 \mathrm{~Sv}$ at $\mathrm{G}$, a sampling error associated with the large separation distance of $\mathrm{P} 2$ and $\mathrm{P} 3$, which is close to the decorrelation length scale. Other $\mathrm{CM}$ moorings are more closely spaced and hence associated with smaller errors (Table A1). The observed difference of the CPIES and CM transport means (or bias) is $2 \mathrm{~Sv}$, only a fraction of the estimated CPIES error on the mean (8.7 Sv). Unlike for $\mathrm{CM}$ error, estimated CPIES error does not reduce greatly for the mean because most of the error components are not random (see the appendix). The observed statistics do improve at monthly time scales; the RMS difference is $5 \mathrm{~Sv}$, and the correlation of the two time series is 0.92. Spectral quantities (Figs. 6b,c) are estimated with a multitaper estimator (Percival and Walden 1993). The CPIES and CM spectra are indistinguishable with $95 \%$ certainty, although the CPIES spectrum has more power at time scales shorter than approximately 10 days. At these periods, the coherence squared (Fig. 6c) is largely insignificant, suggesting there is noise among the signals that go into the calculation of geostrophic velocity from CPIES. There are also significant drops in coherence squared at periods near 30 and 20 days, which could conceivably result from cyclostrophic accelerations during meander events that are not captured by CPIES. In theory, the cyclostrophic component could reach $0.5 \mathrm{~m} \mathrm{~s}^{-1}$ in the core of the jet for a meander radius of $100 \mathrm{~km}$; however, there was no evidence for organized cyclostrophic flow in the meander event captured by LADCP data (Leber and Beal 
(a) 1st deployment: mean

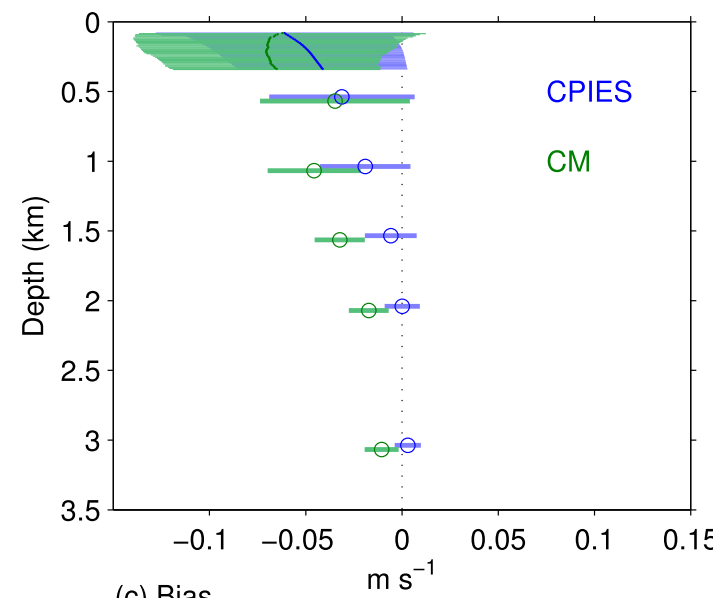

(c) Bias

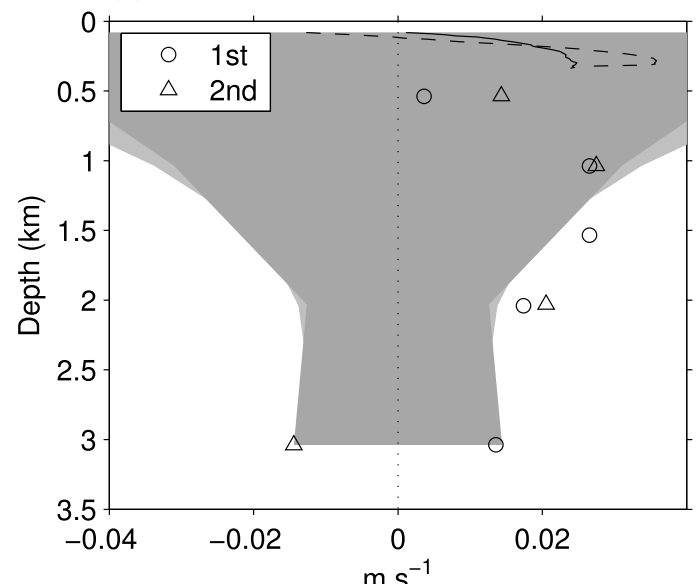

(e) RMS

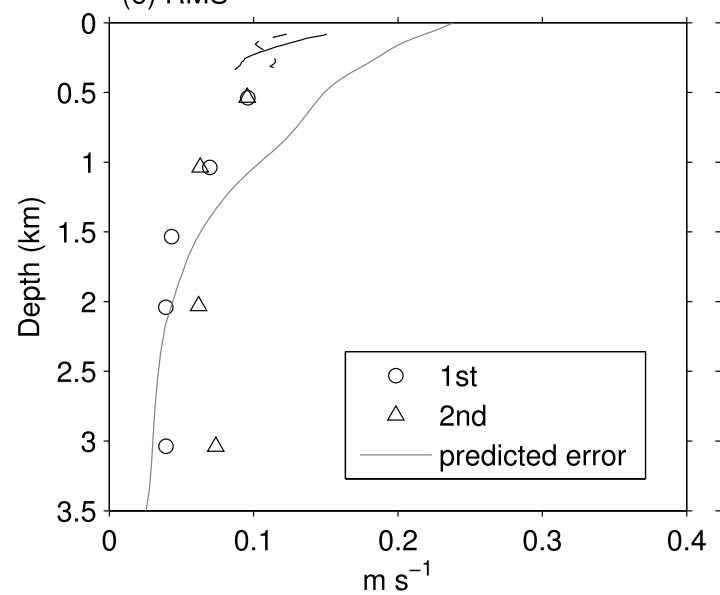

(b) 2nd deployment: mean

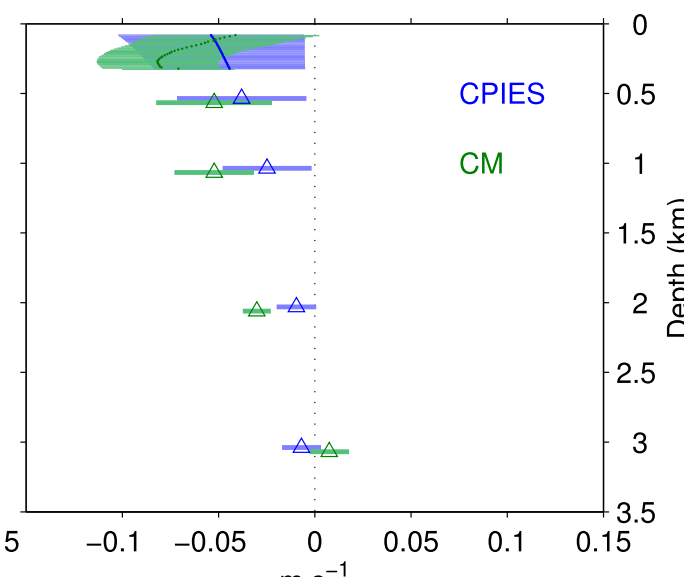

(d) Standard deviation $\mathrm{s}^{-1}$

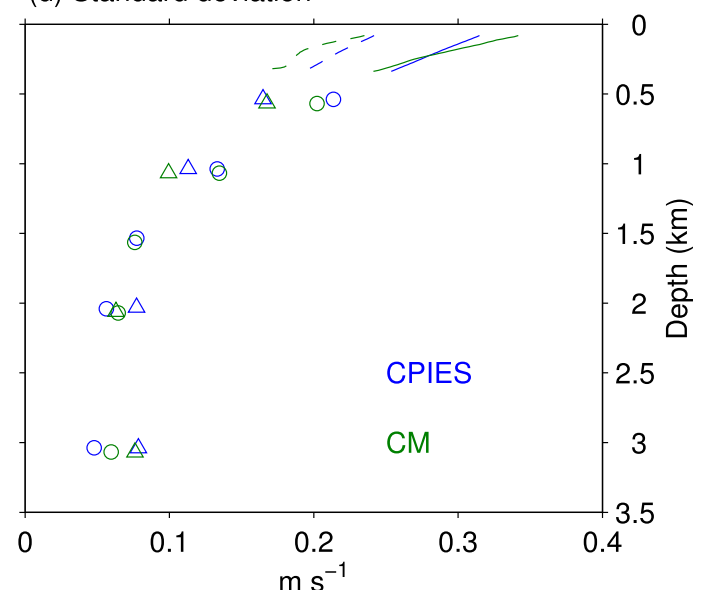

(f) Correlation

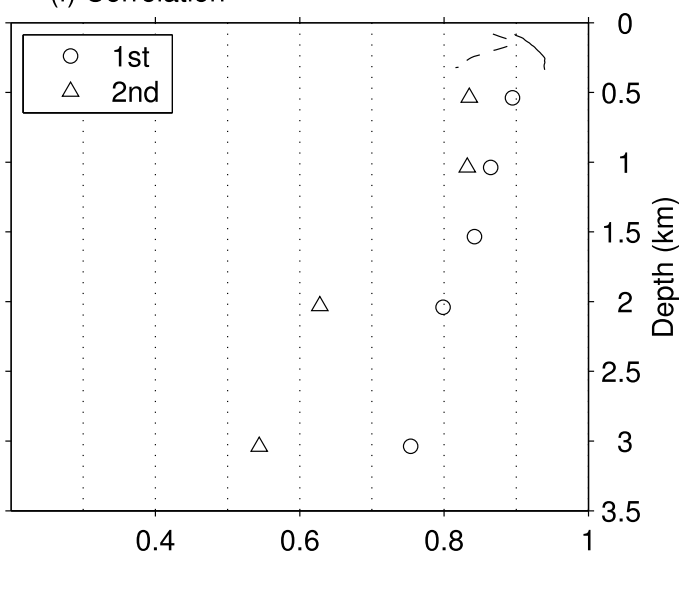

FIG. 5. Comparison between mooring G velocity records (green) and velocities derived from CPIES pair P2-P3 (blue). Both are 20-h interval data with a 40-h low-pass filter. Single-point velocity records are represented by circles for the first deployment and triangles for the second. Near-surface velocity profiles are represented by solid lines for the first deployment and dashed lines for the second. (a) Time-mean velocity (symbols and lines) and its standard error (shading) for the first deployment. (b) As in (a), but for second deployment. (c) Bias error, calculated as the difference in time-mean velocity between CM and CPIES. Shading is the error on the bias. (d) Standard deviation of CM and CPIES velocities. (e) Root-mean-square difference between CPIES and CM velocities. The gray curve is the theoretical CPIES velocity error, as calculated in the appendix. (f) Correlation coefficient between CPIES and CM velocities. 

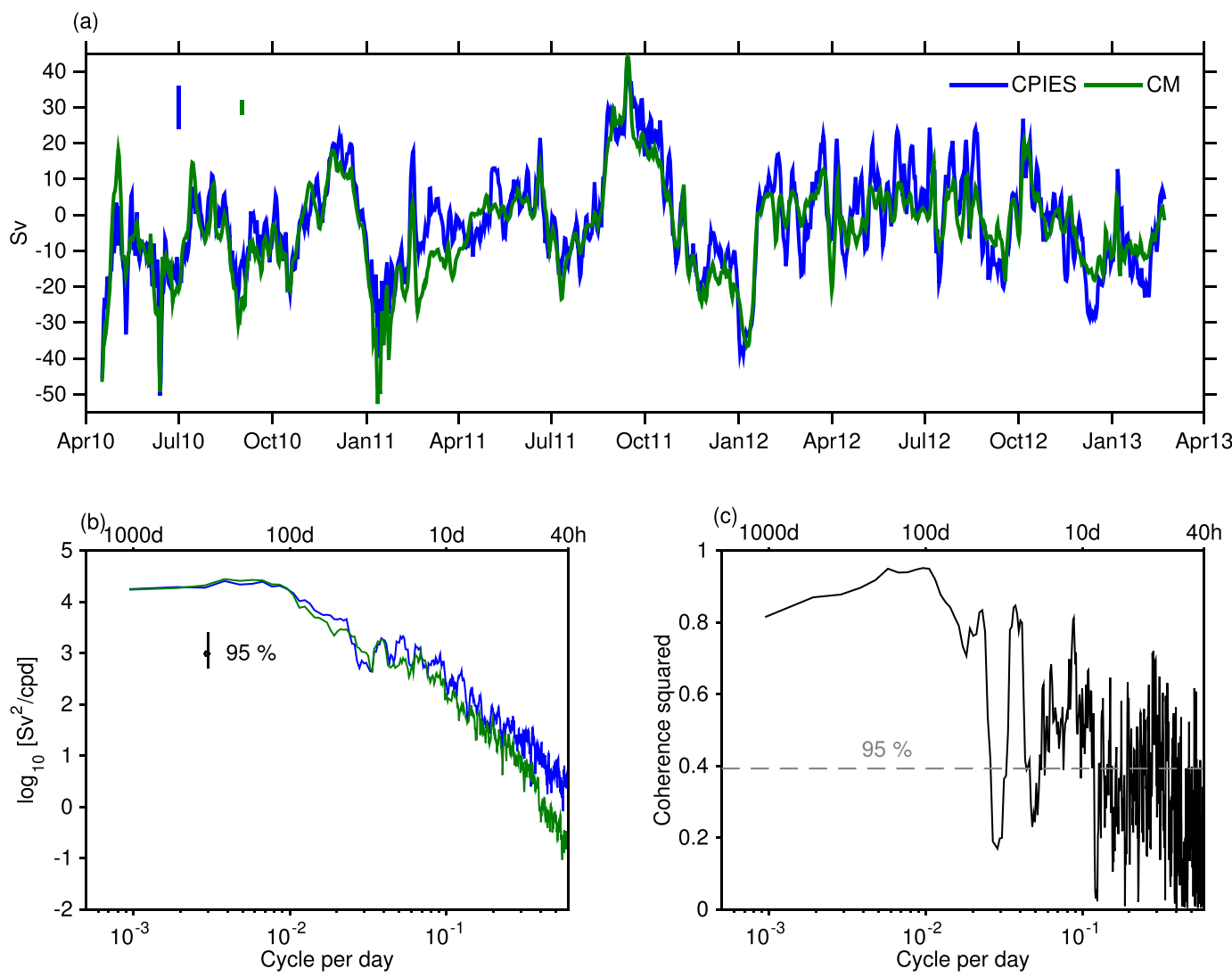

FIG. 6. Comparison between transports from CPIES (blue) and CM (green) at overlapping sites P2-P3 and G. (a) Transport time series (Sv) at 20-h time steps. The error bars show the formal transport errors (on each 20-h time step), as estimated in the appendix and listed in Table 2. (b) Power spectral density calculated using a multitaper estimator with seven Slepian tapers following Percival and Walden (1993). The 95\% confidence interval is based on degrees of freedom equal to twice the number of tapers used for the spectral estimates. (c) Coherence squared between the two transports, with $95 \%$ confidence level.

2014). For periods longer than 40 days, the coherence squared is always larger than 0.65 .

Overall, the agreement between CPIES and CM transports at $\mathrm{G}$ is good, with limitations on the CPIES data at time scales shorter than 1 month and a small positive bias in the mean. The observed errors are substantially smaller than estimated sampling and instrumental errors (appendix).

\section{d. Combining CM and CPIES velocities}

To build a full cross section of the Agulhas Current, we combine all direct velocity profiles from CMs A through $\mathrm{G}$, with the absolute geostrophic profiles estimated from CPIES pairs $\mathrm{P} 3-\mathrm{P} 4$ and $\mathrm{P} 4-\mathrm{P} 5$, to form a gridded velocity section of the current at each 12-h time step. The 40-h low-pass velocity profiles are linearly interpolated in the horizontal onto a $20-\mathrm{m}$ by $500-\mathrm{m}$ grid. High-resolution bathymetry along the section is obtained from multibeam data collected during the first deployment cruise. Over the continental slope, gaps caused by steeply sloping bathymetry are filled by creating "dummy" profiles of constant velocity below sites $\mathrm{A}, \mathrm{B}$, and $\mathrm{C}$ and interpolating linearly in the horizontal. We extrapolate over the shelf $(<70$-m depth) to the coast using a "no slip" condition at the shoreline. Once the grid is filled at each time step, velocities below the seabed are masked. Overall, each gridded cross-section spans the current from the coast out to $300 \mathrm{~km}$ offshore, corresponding to the site of P5. Positive cross-track velocities point approximately toward the northeast $\left(64^{\circ}\right)$, and negative velocities point toward the southwest $\left(244^{\circ}\right)$.

\section{Results}

\section{a. Velocity structure and variability}

The variability of the Agulhas Current is significantly different between the first and second deployments of the ACT array, and hence we show mean and standard deviation of cross-track velocity for each deployment 
TABLE 2. Comparison of transports derived from CPIES vs CM at overlapping sites P2-P3 and G. The top third of the table shows the statistics of each time series, the middle shows the comparison statistics, at the bottom are estimated transport errors, as described in the appendix.

\begin{tabular}{|c|c|c|c|}
\hline & CPIES & & $\mathrm{CM}$ \\
\hline Decorrelation time scale (day) & 15 & & 17.5 \\
\hline Mean (Sv) & -2.1 & & -4.1 \\
\hline Standard deviation $\sigma(\mathrm{Sv})$ & 13.7 & & 12.7 \\
\hline $\begin{array}{l}\text { Standard error of the } \\
\text { mean } \sigma / \sqrt{N}(\mathrm{~Sv})\end{array}$ & 1.6 & & 1.6 \\
\hline Bias (CPIES - CM) (Sv) & & 2.0 & \\
\hline RMS difference, $20 \mathrm{~h}(\mathrm{~Sv})$ & & 7.1 & \\
\hline RMS difference, 1 month (Sv) & & 5.0 & \\
\hline Correlation, $20 \mathrm{~h}$ & & 0.87 & \\
\hline Correlation, 1 month & & 0.92 & \\
\hline Estimated error, $20 \mathrm{~h}(\mathrm{~Sv})$ & 10.5 & & 3.0 \\
\hline Estimated error on the mean $(\mathrm{Sv})$ & 8.7 & & 0.4 \\
\hline
\end{tabular}

separately in Figs. 7 and 8. The similarities of the mean fields are clear: the Agulhas Current jet, defined as the negative (southwestward) flow, is on average $220 \mathrm{~km}$ wide and about $3000 \mathrm{~m}$ deep. Vectors show that the mean flow is in a direction of $230^{\circ}$, at an angle of $15^{\circ}$ to the east of the cross track, reflecting the true alongshore orientation at this latitude. The core of the current is situated a few kilometers off the shelf break at mooring B and shifts offshore with depth, such that the fastest flow at $1500 \mathrm{~m}$ occurs at a distance coincident with the foot of the continental slope or about $50 \mathrm{~km}$ farther offshore at D. This offshore progression of the core with depth is seen in the Agulhas Current farther north and in other western boundary currents, such as the Gulf Stream, even after detachment (Beal and Bryden 1999; Halkin and Rossby 1985). An undercurrent with northeastward flow hugs the slope below $1200 \mathrm{~m}$ and is weaker and deeper, but broader, than the undercurrent observed at $32^{\circ} \mathrm{S}$ (Beal and Bryden 1997; Beal 2009). The greatest variability of the flow is coincident with the core of the current, or slightly inshore at the shelf break, and is strongly anisotropic, with the principal axis aligned alongshore with the mean flow (Fig. 8). This is where the current and its variability are strongly steered by the continental slope. The variance of the flow is a minimum within the anticyclonic side of the Agulhas jet, captured by moorings $\mathrm{C}$ to $\mathrm{F}$, and increases again at the offshore flank of the jet, where it is largely isotropic. Standard deviations at $\mathrm{P} 3-\mathrm{P} 4$ and $\mathrm{P} 4-\mathrm{P} 5$ are geostrophic and hence only available in directions perpendicular to the array.

The differences between the two deployments are because of the influence of solitary meander events, or Natal Pulses (van Leeuwen et al. 2000), on the Eulerian structure of the Agulhas Current (Figs. 7, 8). These mesoscale meanders propagate downstream within the Agulhas Current as a single trough or cyclone. Examining a movie of 12-hourly cross-track velocity sections (ACT movie, supplemental information), we note four meander events during ACT, all occurring during the first deployment. At $\mathrm{ACT}$, these events can be defined as when the core of the current (maximum negative velocity) is displaced offshore to mooring D or beyond; an amplitude of about $100 \mathrm{~km}$. The average duration of meander events on the ACT line is $19 \pm 7$ days. The effect of these displacements on the velocity structure is to weaken and broaden the mean flow during the first deployment and increase its variance all the way across the section down to at least 1000-m depth. The core of the current, defined between the $1 \mathrm{~m} \mathrm{~s}^{-1}$ isotachs, is $50 \mathrm{~km}$ wide during the first deployment and $30 \mathrm{~km}$ wide during the second. The core is broadened in the onshore direction as well as offshore, implying that during a solitary meander event there is displacement of the current onto the shelf, as well as the larger displacement offshore. This was also reported in the mooring data of Bryden et al. (2005) farther north, who found evidence that the Agulhas Current moves onshore at the leading edge of a meander. In the absence of meander events during the second deployment, offshore flows over the CPIES appear more organized and average northeastward. The strength of the undercurrent is also influenced by meanders, with mean northeastward flows of $6 \mathrm{~cm} \mathrm{~s}^{-1}$ at 2500- and 3000-m depth during the second deployment, compared to negligible deep flows during the first.

A meander event was captured by LADCP measurements for the first time during the ACT cruise in April 2010 (Leber and Beal 2014). During the meander, the Agulhas Current is completely detached from the continental slope, with the core shifted $90 \mathrm{~km}$ offshore into waters over $3000 \mathrm{~m}$ deep (Fig. 9). A cyclonic anomaly appears inshore, with northeastward flow reaching full depth over the slope. We were fortunate to capture this event in one-time data since a meander was present at the ACT line less than $10 \%$ of the time ( 77 out of 1044 days). The ACT movie (see the supplemental information) shows that this is a representative meander event in terms of offshore displacement. Importantly, the width of the current, as defined by the $10 \mathrm{~cm} \mathrm{~s}^{-1}$ isotach, is fully captured within the ACT array during all four mesoscale meanders. The LADCP sections of November 2011 and February 2013 (Fig. 9) show the more typical case of an Agulhas Current attached to the slope, stronger and narrower than the time series mean (Fig. 7) but with the core similarly positioned at $40 \mathrm{~km}$ offshore. The mean of these six one-time sections depicts a very broad current (Fig. 9, bottom panel), heavily biased by the meander event and not representative of the time series mean. 

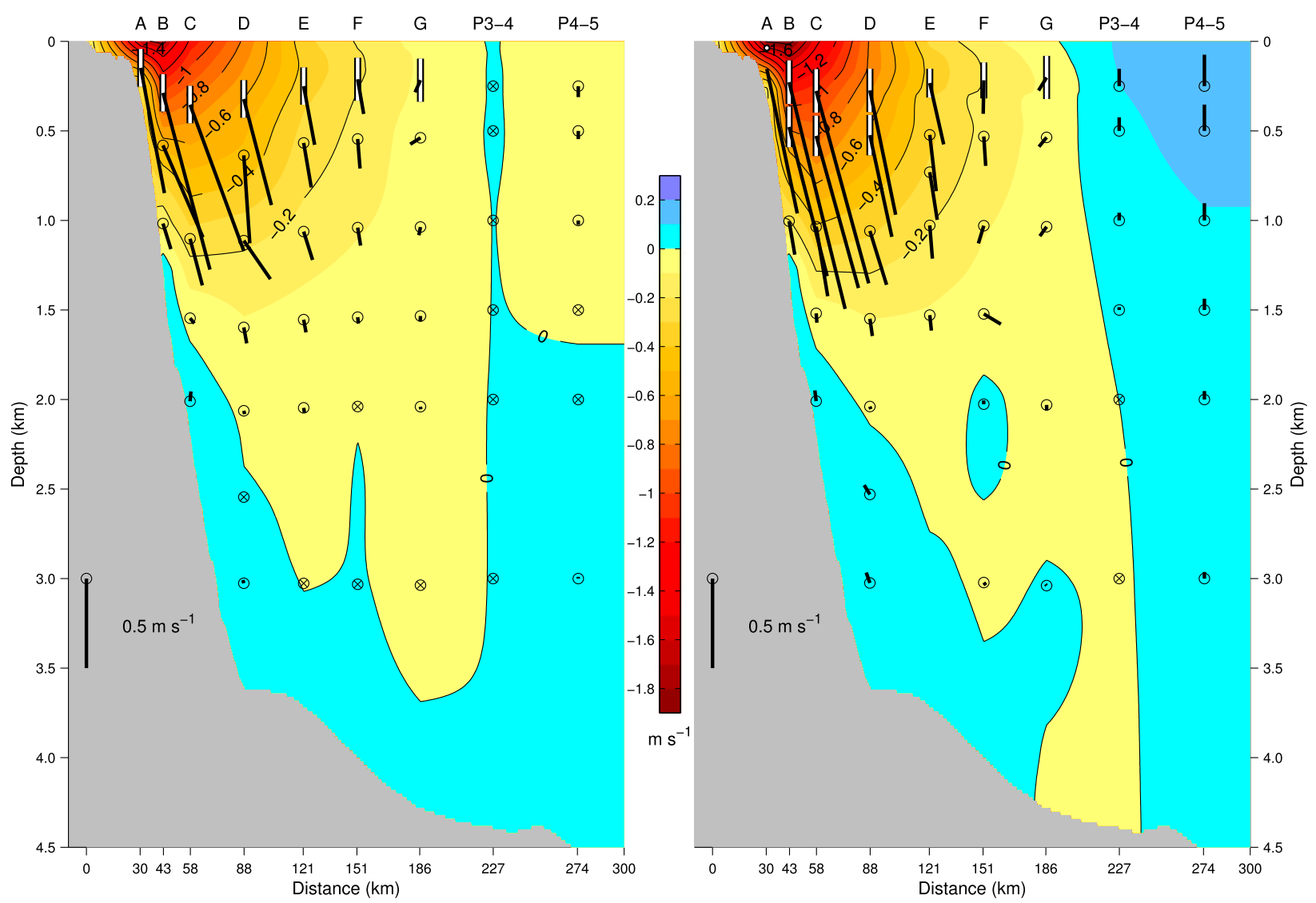

FIG. 7. Time-mean cross-track velocity structure of the Agulhas Current at the ACT array for the (left) first and (right) second deployments, with vector means superposed. Negative, southwestward flow is shaded red through yellow, while positive northeastward flow is shaded in blue. Contours are at intervals of $0.2 \mathrm{~m} \mathrm{~s}^{-1}$. The origins of the vectors are drawn as dots at the average depths of the ADCM measurements and as lines for the average length of ADCP profiles. Vectors from CPIES pairs are shown for discrete depths, although velocity profiles from the GEM are continuous. For the second deployment, the long-range ADCP profiles at moorings B, C, and D are depicted by two vectors. Velocity vectors are rotated to array coordinates so that vectors pointing to the right in the core of the current represent the true alongshore direction. The scale for the velocity vectors is shown at bottom left. Mean velocity vectors less than $0.01 \mathrm{~m} \mathrm{~s}^{-1}$ are indicated by an X. Positions of current meter moorings A through G and CPIES pairs P3-P4 and P4-P5 are shown along the top axis. Bathymetry is shaded gray.

\section{b. Transport time series}

From our velocity cross sections we define boundaries of integration to yield the transport of the Agulhas Current at each time step. Defining these boundaries is not straightforward and transports are highly "definition dependent" (Hogg and Johns 1995). The current might best be considered as the flow between surface crossings of the zero isotach, but we find that this flow is ill defined at many time steps because negative anomalies impinging on the current from the east obscure the offshore surface zero crossing (ACT movie, supplemental information). Another consideration is whether the current constitutes the net flow or only the southwestward flow? A net transport includes northeastward flows that flank the main current, and these can be argued to be an intrinsic part of the western boundary current, for instance, forming part of the Munk boundary layer or an inertially or eddy-driven recirculation gyre (Munk 1950; Cessi 1990; Holland and Rhines 1980). Yet, offshore counter flows are not captured consistently within the length of our array, and, in the case of the Agulhas, there is no evidence for a recirculation gyre (Casal et al. 2009).

We choose to calculate two transport time series: the first we call the boundary layer transport $T_{\text {box }}$, and the second we call the western boundary jet transport $T$. The term $T_{\text {box }}$ is the net transport within a fixed distance of the coast, a common definition from moored arrays. This is similar to the definition of Agulhas Current transport as measured at $32^{\circ} \mathrm{S}$ during WOCE in 1995/96 (Bryden et al. 2005). Bryden et al. (2005) calculated daily net transport out to $203 \mathrm{~km}$ offshore (the mean position of their extrapolated zero velocity isotach) from an array of five moorings spanning the current 


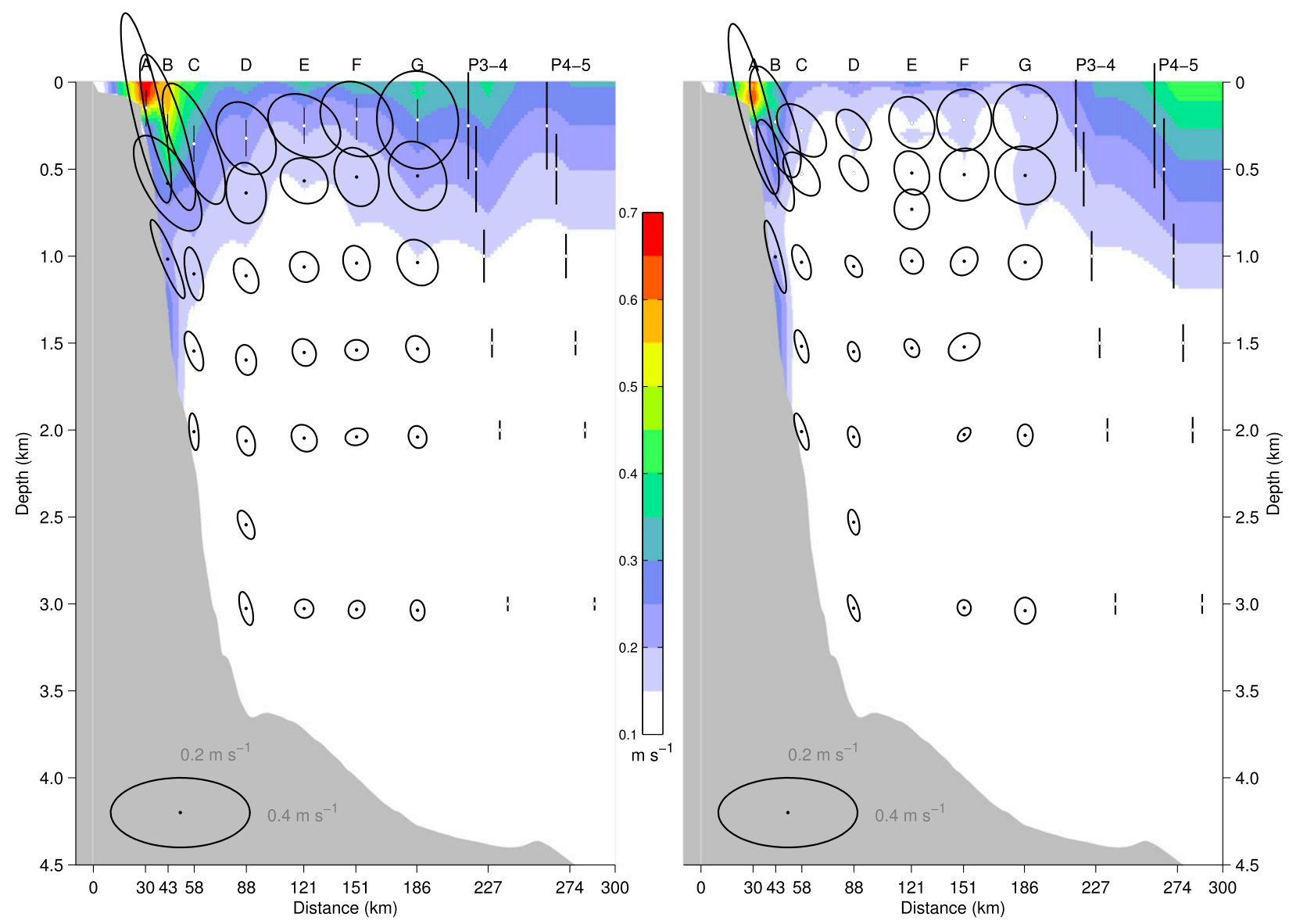

FIG. 8. As Fig. 7, but for standard deviation of cross-track velocity with variance ellipses superposed. The largest deviations are shaded red, with shading changes at $0.05 \mathrm{~m} \mathrm{~s}^{-1}$ intervals. The locations of the CPIES pairs are offset horizontally with depth for legibility of the deviations. The ellipses are rotated to array coordinates so that a major axis oriented vertically represents cross-track variability. The scalloping of the standard deviation contours from the gridded velocity is an artifact of the horizontal linear interpolation between moorings.

between 20 and $153 \mathrm{~km}$ offshore. Extrapolation $50 \mathrm{~km}$ beyond the offshore mooring was by constant horizontal velocity shear. Here, we calculate a similar $T_{\text {box }}$ at the ACT array. We integrate vertically to the seabed with the trapezoidal method to obtain transport per unit distance $T_{x}\left(\mathrm{~m}^{2} \mathrm{~s}^{-1}\right)$ and then cumulate from the coast out to $219 \mathrm{~km}$ offshore the time-mean position of our zero isotach. Offshore extrapolation is unnecessary in our case since the ACT array captures the mean width of the current. The resulting transport time series, its distribution, and frequency characteristics are plotted in Fig. 10, and its statistics are summarized in Table 3. The record-length (1044 days) mean and standard error of this boundary layer transport at $34^{\circ} \mathrm{S}$ is $-77 \pm 4 \mathrm{~Sv}$.

For a direct comparison with the transport measured at $32^{\circ} \mathrm{S}$, we calculate an exact equivalent transport at $34^{\circ} \mathrm{S}$. Owing to lack of deep observations, Bryden et al. (2005) integrated transport to $2400 \mathrm{~m}$, which they estimated to be $200 \mathrm{~m}$ below the (extrapolated) mean depth of the current in deep water. Hence, we integrate to 3100-m depth at ACT, where the current penetrates to $2900 \mathrm{~m}$ on average. This yields a mean of $-79 \mathrm{~Sv}$ or $10 \mathrm{~Sv}$ greater than the transport at $32^{\circ} \mathrm{S}$. This difference corresponds to a largely baroclinic (vertically sheared) downstream increase of $2.4 \mathrm{~Sv}$ per $100 \mathrm{~km}$ in the Agulhas Current and is equal to the increase in Sverdrup transport predicted from the winds at these latitudes (Casal et al. 2009). Hence, there is no evidence for a barotropic recirculation gyre, as also noted by Casal et al. (2009).

For the western boundary jet transport $T$ we look for a stream-dependent definition where the boundaries of integration, and hence transport variability, depend on the strength and cross-sectional area of the southwestward Agulhas jet at each time step. Defined in this way, $T$ excludes northeastward counterflows on the inshore and offshore flanks of the jet, which could bias transport high if these counterflows contribute to local recirculations. However, $T$ is more consistent in its definition than $T_{\text {box }}$, 

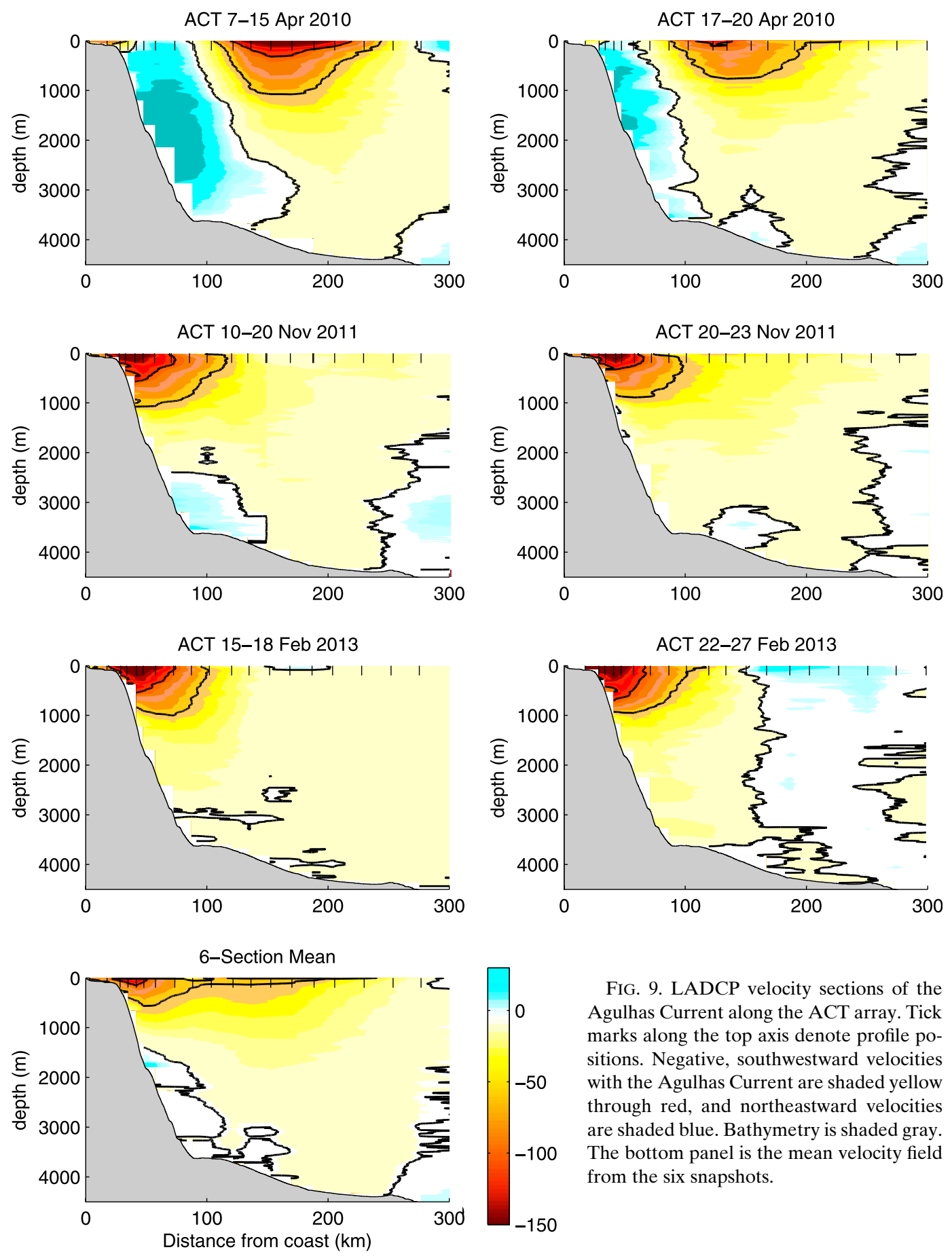

FIG. 9. LADCP velocity sections of the Agulhas Current along the ACT array. Tick marks along the top axis denote profile positions. Negative, southwestward velocities with the Agulhas Current are shaded yellow through red, and northeastward velocities are shaded blue. Bathymetry is shaded gray. The bottom panel is the mean velocity field from the six snapshots.

which can only account for onshore counterflows, while missing those offshore. Other strengths are that $T$ is able to capture the whole current during meander events and is objectively reproducible in simulations, where its definition remains exactly equivalent regardless of grid resolution and hence boundary layer thickness, which would affect $T_{\text {box }}$.

The time-varying jet can have a complex structure (ACT movie, supplemental information), and it took a few iterations to find a simple and objective algorithm that could identify the jet satisfactorily at each time step. We calculate $T_{x}$ at each time step, low-pass filter using the decorrelation length scale of $56 \mathrm{~km}$, and then look for the position of the first maximum beyond the 

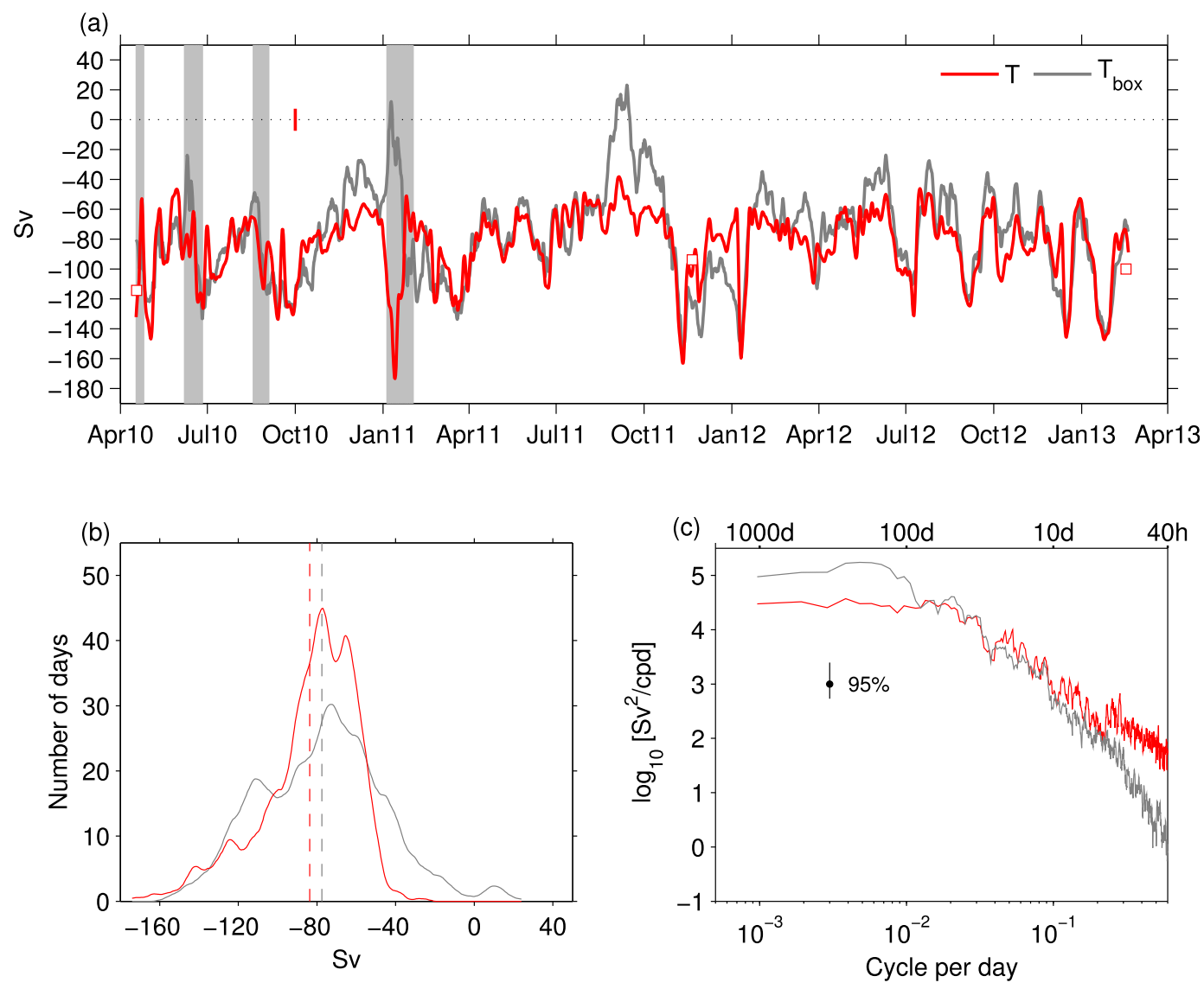

FIG. 10. (a) Agulhas Current jet transport time series $T$ (red) and boundary layer transport time series $T_{\text {box }}$ (gray). The time series of $T$ is smoothed with a 5-day low-pass filter. Gray shading highlights meander events. Red squares are LADCP transports. The error bar indicates the estimated error (see the appendix) and is an upper bound. (b) Probability density functions for $T$ and $T_{\text {box }}$ estimated using a Gaussian kernel with optimal bandwidth (Silverman 1986). The vertical dashed lines indicate mean values. (c) Power spectral density of $T$ and $T_{\text {box }}$, estimated using a multitaper estimator with seven Slepian tapers (Percival and Walden 1993).

half-width of the jet $(110 \mathrm{~km}), x_{\max }$. We then take $T$ as the southwestward component of transport integrated out to $x_{\max }$. Defined in this way, the Agulhas jet is fully captured within the ACT array $\left(x_{\max }<300 \mathrm{~km}\right) 96 \%$ of the time, although the exact location of the offshore flank of the jet is poorly defined because transport is constant across the widely spaced CPIES pairs.

The record-length (1044 days) mean and standard error of the western boundary jet transport at $34^{\circ} \mathrm{S}$ is $-84 \pm$ 2 Sv (Fig. 10; Table 3). We find good agreement between $T$ and equivalent transports from the one-time, highresolution LADCP transects (Fig. 10a). The transport $T$ has a decorrelation time scale of 7 days, less than half the time scale for $T_{\text {box }}$. The reduction in the decorrelation time scale for $T$ is owing to its lower power at long periods (Fig. 10c), which is potentially advantageous for the detection of annual and interannual signals. At short periods, the spectrum of $T$ is contaminated by some discontinuities in transport related to rapid jumps in the limit of integration, particularly during meander events. For meanders propagating along the boundary from upstream, the array orientation creates a phase lag between the onshore and offshore ends of the array, giving the appearance of a double jet at the leading and trailing edges of a meander, which leads to ambiguity. Both transport distributions are skewed (Fig. 10b), failing the Kolmogorov-Smirnov test for Gaussian distribution at the $5 \%$ confidence level. Transport $T_{\text {box }}$ is skewed positive (0.17) because of missing poleward transport during meander events, while $T$ is skewed negative $(-0.9)$, perhaps because of the missing recirculations, with a sharp cutoff at a minimum Agulhas strength of $-40 \mathrm{~Sv}$ and a long tail out to a maximum transport of $-170 \mathrm{~Sv}$.

Formal estimates of transport uncertainty arising from instrumental and sampling errors are $9 \mathrm{~Sv}$ on the mean from CPIES data and $0.5 \mathrm{~Sv}$ from CM data (Table 3 ; and the appendix). For the CM data, sampling errors are an order of magnitude larger than instrumental 
TABLE 3. Statistics (Sv) of time series for the western boundary jet transport $T$ and the boundary layer transport $T_{\text {box }}$. Negative values are transport to the southwest with the Agulhas Current. Estimated errors are an upper bound and propagate from the derivation of geostrophic velocity from CPIES and from CM instrumental and sampling errors, as described in the appendix.

\begin{tabular}{lcc}
\hline \hline & $T$ & $T_{\text {box }}$ \\
\hline Mean & -84 & -77 \\
Median & -79 & -76 \\
Standard deviation & 24 & 32 \\
Decorrelation time scale & 7 & 17 \\
Standard error of the mean & 2 & 4 \\
Estimated error (20 h) & 14.8 & 6 \\
Estimated error (mean) & 9.0 & 0.5 \\
\hline
\end{tabular}

errors, while for CPIES data these errors are similar (see the appendix). As seen above, observed differences between overlapping CPIES- and CM-derived transports (Table 2 ) show actual CPIES errors are likely $30 \%$ smaller than these estimates. Nevertheless, we combine these independent CM and CPIES errors and sum with the standard error (Kanzow et al. 2010) to estimate a mean and total error for the western boundary jet transport of $-84 \pm 11 \mathrm{~Sv}$. This total error is an upper bound since $T$ is dependent on CPIES data only $40 \%$ of the time. For $T_{\text {box }}$, which is integrated only over the CM array, the mean and total error amount to $-77 \pm 5 \mathrm{~Sv}$.

The effect of meander events on the time series of $T$ and $T_{\text {box }}$ is markedly different (gray shading; Fig. 10a). Four solitary meander events propagated across the ACT array all within the first year. Maximum core displacements occur on 16 April 2010 (during the first ACT cruise; Leber and Beal 2014), 10 June 2010, 28 August 2010 , and 10 January 2011. There is a strong minimum in $T_{\text {box }}$ during each event caused by inshore northeastward flow around the trough and, more importantly, by missing southwestward transport in the portion of the Agulhas Current outside the boundary of integration. In contrast, the jet transport appears to increase slightly (to the southwest) during each meander event. This increase may also result from a local recirculation of jet waters around the trough, which would be balanced by northeastward flow at the coast not captured by $T$. Transport anomalies associated with meanders are within one standard deviation, except during the longest meander event in January 2011.

Transport $T$ has noticeably less power than $T_{\text {box }}$ at time scales longer than 80 days, although statistically the spectra are the same within the $95 \%$ confidence intervals. This difference may be related to the separation of jet and eddy variability achieved by the algorithm for $T$. Also, we notice peaks in the power spectral density of $T_{\text {box }}$ centered at a period of 50 days (bandwidth 31 to 123 days), similar to previously observed meander time scales (Bryden et al.
2005; Beal 2009), and at 11.5 days (Fig. 10c), a period associated with wind-forced, coastally trapped waves that propagate upstream in this region (Schumann and Brink 1990). These peaks are not discernible in the spectrum of $T$, which is noisier, but suggests that the meandering of the current is not related to changes in its jet transport, as also found by Leber and Beal (2014). In fact, we find that higher transports are related to a broader and deeper Agulhas Current jet, associated with a strengthening of the first baroclinic mode, as shown in the transport composites of Fig. 11. In the low transport state, the current is narrow, less than $150 \mathrm{~km}$ wide, and there is a recirculation, or perhaps a cyclonic anomaly, offshore. There is no difference (greater than the mooring spacing) between the position of maximum surface velocities in the current core during high and low transport states.

ACT represents the longest time series of Agulhas Current transport to date and can provide clues about its annual cycle, which is so far unknown. We estimate annual cycles for both $T$ and $T_{\text {box }}$ and find that both time series exhibit maxima in August and minima in January and March, respectively (Fig. 12). This suggests that the Agulhas Current is strongest in austral summer and weakest in winter. Our annual cycle has the same phase as that implied by Krug and Tournadre (2012) from $18 \mathrm{yr}$ of along-track satellite altimeter data. Using a crossstream coordinate approach, they found the geostrophic speed at the current core to be strongest in austral summer. However, it is opposite the annual cycle farther north in the Mozambique Channel (Ridderinkhof et al. 2010), which is strongest in austral winter, and is also opposite the annual cycle of wind stress curl at $30^{\circ} \mathrm{S}$. Moreover, it does not match the annual cycle reported in simulations (Biastoch et al. 1999; Matano et al. 2008), which pointed to maximum transport in winter-spring and minimum in summer. Clearly there is future work to be done to understand and simulate the seasonal cycle of the Agulhas Current correctly.

\section{Summary and discussion}

The ACT array successfully measured 34 months of Agulhas Current velocity and transport variability. The use of CPIES extended the traditional current meter array farther offshore, so that, for the first time, we were able to capture the full Agulhas Current jet at all times, even during mesoscale meander events. Transports derived from CPIES were in agreement with overlapping transports measured directly from a current meter mooring, with a zero-lag correlation of 0.89 and a bias of $+2.0 \mathrm{~Sv}$ on the mean. Overall, the upper limit of CPIES error, estimated from first principles, amounts to $9.0 \mathrm{~Sv}$ on our mean Agulhas transport, with 

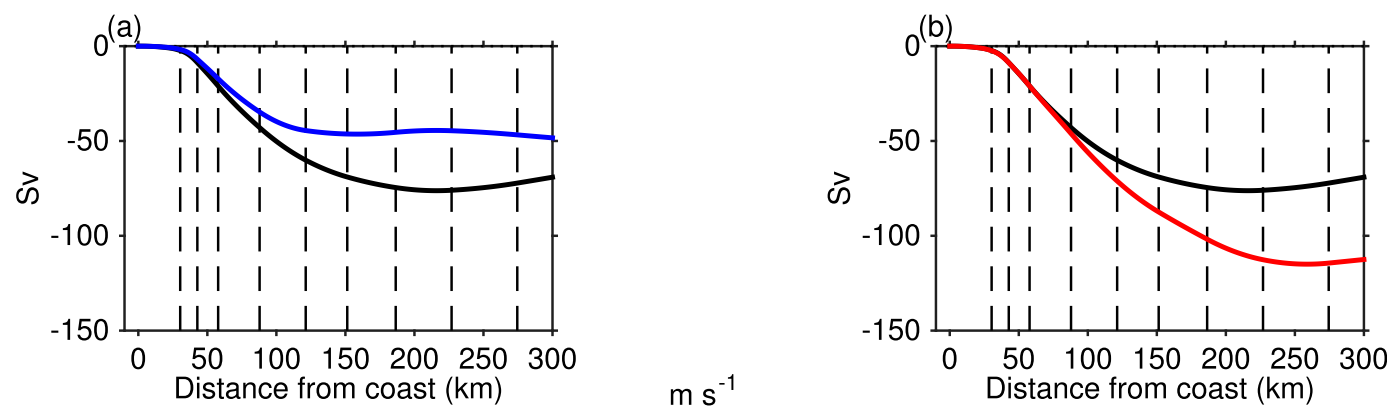

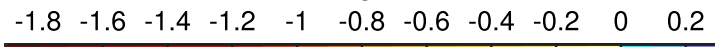

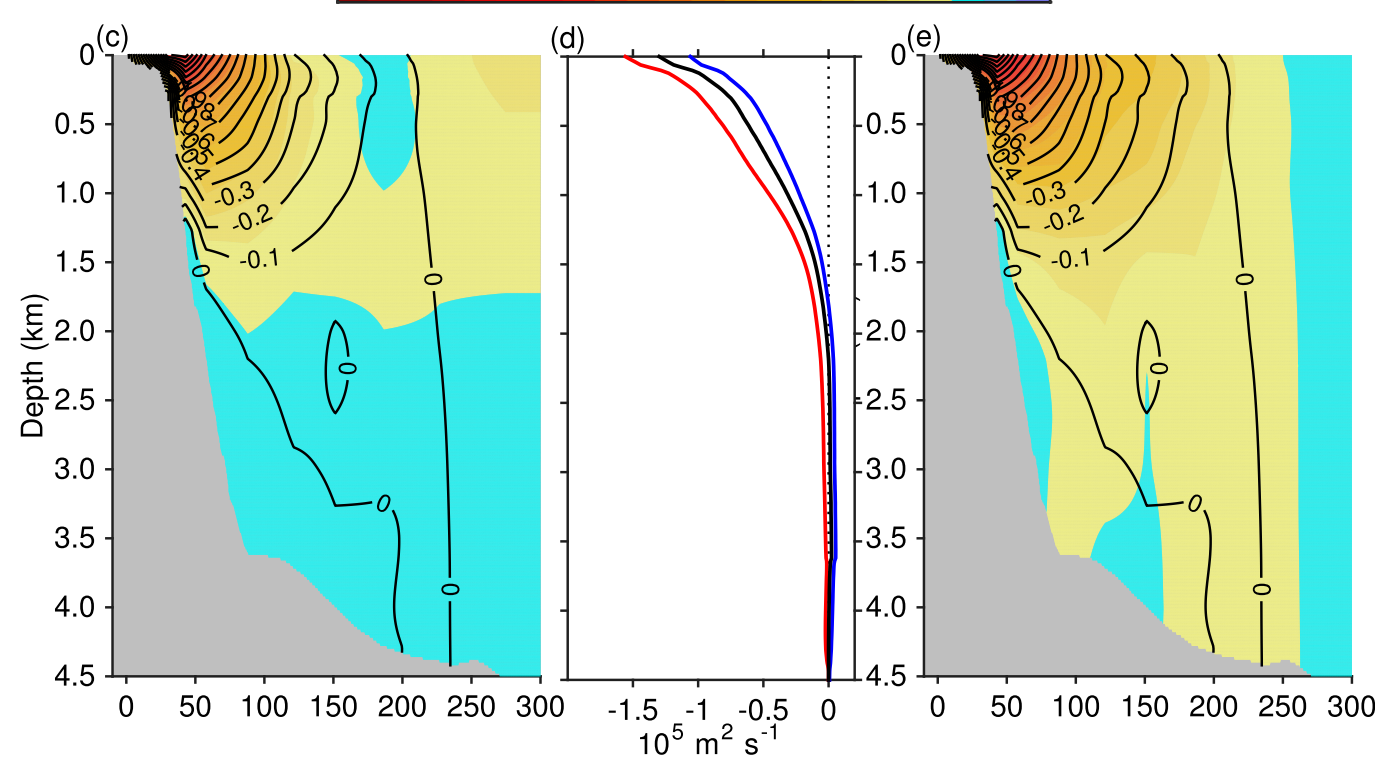

FIG. 11. Composites of 12-hourly, cross-track velocity fields from the ACT array corresponding to (c) the $10 \%$ lowest transports and (e) the $10 \%$ highest transports of the western boundary jet time series. Note that negative, southwestward velocities with the Agulhas Current are shaded red through yellow, while northeastward velocities are shaded blue. Black contours depict the time-mean velocity structure. (a),(b) Transport (Sv) cumulated offshore for the high transport composite (red), low transport composite (blue), and the mean (black). Positions of the moorings and CPIES pairs are indicated by dashed lines. (d) Transport per unit depth $\left(\mathrm{m}^{2} \mathrm{~s}^{-1}\right)$ for the high (red), low (blue), and mean (black) transport states.

the overlapping observations implying a real error about $30 \%$ less than this. Instrumental and sampling errors from the current meter array amount to $0.5 \mathrm{~Sv}$ on the mean.

The Eulerian mean Agulhas Current is $219 \mathrm{~km}$ wide and $3000 \mathrm{~m}$ deep, with peak surface velocities of $1.8 \mathrm{~m} \mathrm{~s}^{-1}$ and a weak northward undercurrent on the continental slope below $1200 \mathrm{~m}$. We develop a simple algorithm to define the Agulhas Current jet at every time step and find a mean jet transport of $-84 \mathrm{~Sv}$, with a standard error of $2 \mathrm{~Sv}$. Including instrumental and sampling errors from above, this amounts to $-84 \pm 11 \mathrm{~Sv}$. A more traditional estimate of boundary layer transport, based on net transport integrated out to a fixed distance of $219 \mathrm{~km}$ offshore, gives a mean of $-77 \pm 5 \mathrm{~Sv}$. This implies an increase of $2.4 \mathrm{~Sv}$ per $100 \mathrm{~km}$ between the former WOCE array at $32^{\circ} \mathrm{S}$ and the ACT array downstream at $34^{\circ} \mathrm{S}$, equal to the increase in Sverdrup transport over these latitudes.

The distribution of Agulhas Current transports drops off sharply at $-40 \mathrm{~Sv}$ and has a long tail toward the strongest transport of $-170 \mathrm{~Sv}$. Strong transports correspond to a deepening and widening of the current, with a strengthening of its baroclinic structure, while weak transports are associated with a narrow, shallow jet. There is negligible change in the position of the Agulhas Current core (surface velocity maximum) with respect to transport. Variance in velocity is a maximum at the inshore edge of the current over the shelf break, where it is strongly aligned with topography, is smallest just offshore of the current core, and increases again at the offshore flank of the current where the variance is isotropic. 


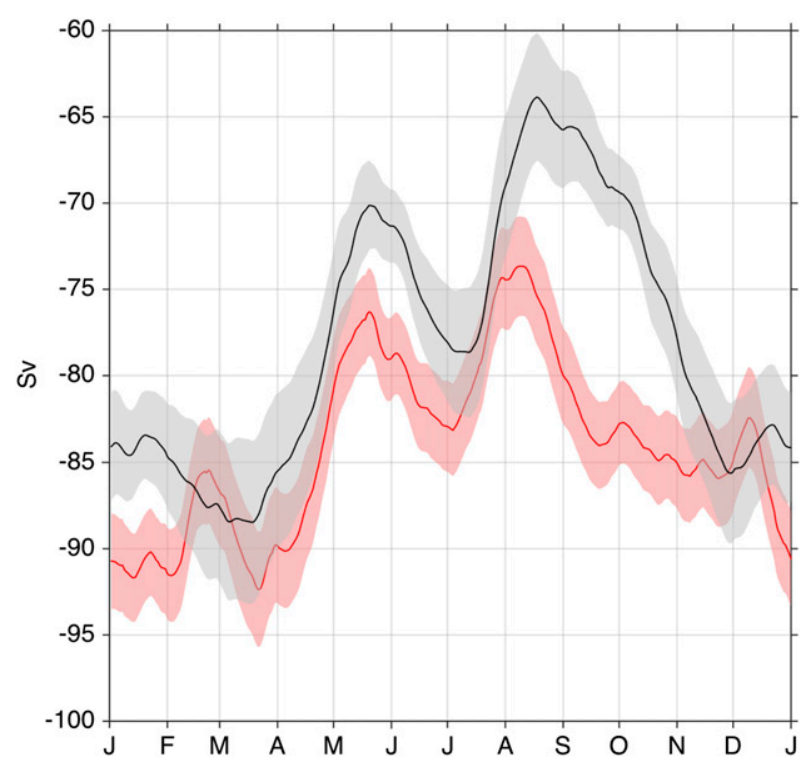

FIG. 12. Annual cycles of western boundary jet transport: $T$ in red and boundary layer transport $T_{\text {box }}$ in gray. Curves are obtained using the Nadaraya-Watson kernel estimator with a Gaussian kernel of half-width 30 days (Fan and Gijbels 1996).

The power spectra of the boundary layer and jet transports exhibit some differences that can be related to physical phenomena. The jet transport spectrum has lower power at long periods ( $>80$ days), which we interpret is because of the removal of mesoscale variance. Hence, there is potential for better discernment of annual and interannual signals in this time series. The boundary layer transport appears to have enhanced energy at periods related to coastally trapped waves (Schumann and Brink 1990) and mesoscale meander events (Bryden et al. 2005). The suggestion is that these propagating anomalies manifest as onshore-offshore displacements of the Agulhas Current with little effect on its jet transport, although the spectrum of $T$ is too noisy for a robust conclusion.

Four solitary meanders cross the ACT array, all within the first year of observations. In the past, a number of studies have suggested that these solitary meanders may act as an upstream control for the shedding of Agulhas rings by propagating into the retroflection region and destabilizing the flow (Schouten et al. 2002; van Leeuwen et al. 2000). To test this hypothesis, we created a regional movie of satellite sea surface height data over the period of the ACT array and looked for ring-shedding events. We counted 14 events over the 34-month deployment, of which four coincided in time with the four meanders observed at the ACT array. Given that we expect a 3-month lag between meandering and ring shedding, based on the average propagation speed of the meanders $\left(15 \mathrm{~km} \mathrm{day}^{-1}\right.$; van Leeuwen et al. 2000), these coincident events are hard to interpret. These meanders, their sources, and their relation to ring shedding deserve closer investigation, and we are currently synthesizing our observations along the ACT line with satellite sea surface height data for a follow-on study.

In terms of an annual cycle, August transports in the Agulhas Current are significantly weaker than those during austral summer, implying an annual cycle of amplitude about $10 \mathrm{~Sv}$ or $12 \%$ of the mean. The phase and amplitude of this annual cycle are similar to those of the Gulf Stream and Kuroshio, which are also strongest in the summertime (Sato and Rossby 1995; Rossby et al. 2010; Shen et al. 2014). However, this annual signal in Agulhas transport is not successfully captured by simulations (Biastoch et al. 1999; Matano et al. 2008), and hence the forcing of the annual cycle deserves further investigation. The East Madagascar and Mozambique Ridges may be important by deflecting or dispersing Rossby waves from the interior as they approach the western boundary (Matano et al. 2002). Alongshore winds may drive seasonal coastal upwelling/downwelling that could affect transport, as found in the Florida Current (Anderson and Corry 1985; Czeschel et al. 2012). Perhaps planetary wave teleconnections to strong monsoon forcing over the northern Indian Ocean and to tropical Pacific trade winds act to modify the annual cycle of the Agulhas Current (Xie et al. 2002).

Finally, we note that the mean strength of the Agulhas Current, as defined by our western boundary jet transport, is equal to what one would predict from simple steady-state dynamics. Wind stress curl over the Indian Ocean at $34^{\circ} \mathrm{S}$ gives a Sverdrup transport of $60 \mathrm{~Sv}$ (Casal et al. 2009), while components from the Indonesian Throughflow and basinwide thermohaline circulation add another 25 Sv (Lumpkin and Speer 2007; Ganachaud and Wunsch 2000), for a total of $85 \mathrm{~Sv}$ compared to our observed $84 \mathrm{~Sv}$.

Acknowledgments. We dedicate this paper to Robert Jones, who recently retired after more than $25 \mathrm{yr}$ as a mooring technician at RSMAS. Thanks Robert for all your hard work and good advice during ACT! Extreme conditions in the Agulhas require versatile, skillful ship handling, and we are very grateful to the officers and crew of R/V Knorr and R/V Melville, whose professionalism and dedication to the science were key to achieving our mission. The outreach program for ACT was built on a shoestring and owes its quality to Dallas Murphy's extraordinary writing talent (http://act.rsmas. miami.edu/journal/) and to Valery Lyman's professional videography ("Women in Oceanography" and "To Follow the Water," both available on YouTube). Argo data were collected and made freely available by the International Argo Program and the national programs 
that contribute to it (www.argo.ucsd.edu; http://argo. jcommops.org). The Argo Program is part of the Global Ocean Observing System. This work was supported by the U.S. National Science Foundation through the ACT project, Award OCE-0850891.

\section{APPENDIX}

\section{Derivation of Transport Errors from CM and CPIES}

\section{a. Error in CM transport}

There are two types of error associated with the current meter measurements. Instrumental error arises from the accuracy of the ADCM and ADCP velocities, and sampling error arises from the ability of the array spacing to resolve the scales of flow.

Instrument manufacturers specify nominal accuracies; however, since we expect heterogeneity (see section 2), we estimate the accuracies ourselves by examining the velocity power spectra of all instruments (taking the average velocity over all bins for ADCPs). Instrument error corresponds to the frequency integral of the background white noise level in these spectra. These errors range from 0.05 to $1.9 \mathrm{~cm} \mathrm{~s}^{-1}$ and, as expected, are largest at middepth, owing to a well-known minimum in scatterers there. We take the median error from each deployment, that is, $0.7 \mathrm{~cm} \mathrm{~s}^{-1}$ for the first deployment and $0.9 \mathrm{~cm} \mathrm{~s}^{-1}$ for the second, as our instrumental error.

To estimate sampling error, we use the formalism of optimal interpolation (Bretherton et al. 1976), as applied to oceanic transport (Fandry and Pillsbury 1979; Johns et al. 2005). Optimal interpolation (OI) provides an estimate of the true velocity field that minimizes the error variance in a least squares sense, provided that the covariance function of the field is known. Hence, using our observed horizontal and vertical covariance functions, fit from the 40-h low-passed current meter record correlations shown in Fig. 3, we can estimate a sampling error. We assume the covariance functions to have the form (Fandry and Pillsbury 1979)

$$
\rho_{h}(r)=e^{-\left(r / r_{h}\right)^{2}} \cos \left(\frac{\pi r}{2 r_{h}}\right), \text { and }
$$

$$
\rho_{v}(z)=e^{-\left(z / z_{v}\right)^{2}}
$$

where $r_{h}$ and $z_{v}$ are the decorrelation length scales in the horizontal (cross stream) and vertical, respectively. We find $r_{h}=[63,47] \mathrm{km}$ and $z_{v}=$ $[1913,1015] \mathrm{m}$ for the first and second deployments, respectively, using a nonlinear fitting algorithm (Nelder and Mead 1965).

The error variance $\varepsilon_{0}^{2}$ for an OI value at location $x_{0}$, based on two observations at locations $x_{1}$ and $x_{2}$ with common background variance $\sigma_{b}^{2}$, is given by (Daley 1991, chapter 4)

$$
\varepsilon_{0}^{2}=\sigma_{b}^{2}\left[1-\frac{\left.(1+\alpha)\left(\rho_{10}^{2}+\rho_{20}^{2}\right)-2 \rho_{10} \rho_{20} \rho_{12}\right)}{(1+\alpha)^{2}-\rho_{12}^{2}}\right],
$$

where $\alpha=\sigma_{r}^{2} / \sigma_{b}^{2}$ is the ratio of noise to background variance, and $\rho_{i j}$ is the correlation between values at locations $x_{i}$ and $x_{j}$. Here, we use this expression to calculate the velocity error variance at the middistance point between a pair of moorings with separation distance $\Delta x$. Noise is the aforementioned instrumental error. For background variance we use a single vertical profile of velocity variance $\sigma_{b}(z)$, obtained by horizontally averaging across the array. The horizontal correlations come from Eq. (A1), such that $\rho_{10}=\rho_{20}=\rho_{h}(\Delta x / 2)$ and $\rho_{12}=\rho_{h}(\Delta x)$.

We need to propagate these velocity error variances into our transport estimate. For each $\mathrm{CM}$ pair, trapezoidal integration in the horizontal implies an error variance for transport per unit depth of $\sigma_{T_{z}}^{2}=(\Delta x)^{2} \varepsilon_{0}^{2}$. Thus, the transport error variance is obtained by propagating $\sigma_{T_{z}}^{2}$ through the vertical integral from the seabed $(z=-H)$ to the surface, taking into account the vertical correlation of velocity:

$$
\sigma_{T}^{2}=\int_{-H}^{0} \int_{-H}^{0}(\Delta x)^{2} \rho_{v}\left(\left|z_{2}-z_{1}\right|\right) \varepsilon_{0}\left(z_{1}\right) \varepsilon_{0}\left(z_{2}\right) d z_{1} d z_{2} .
$$

Similarly, the error variance for the net transport across the whole CM array is obtained by taking into account both horizontal and vertical correlations, formally:

$$
\sigma_{T_{\mathrm{box}}}^{2}=\int_{x} \int_{x} \int_{-H(x)}^{0} \int_{-H(x)}^{0} \rho_{v}\left(\left|z_{2}-z_{1}\right|\right) \rho_{h}\left(\left|x_{2}-x_{1}\right|\right) \varepsilon_{0}\left(z_{1}\right) \varepsilon_{0}\left(z_{2}\right) d z_{1} d z_{2} d x_{1} d x_{2} .
$$

In practice, the horizontal integrals in Eq. (A5) are calculated discretely for each CM pair. This estimate neglects the regions inshore of mooring A (very small) and between $\mathrm{G}$ and P3. In Table A1, we summarize the transport errors from each deployment, also showing the case where the instrumental error $\sigma_{r}=0$. The overall 
$\mathrm{CM}$ transport error is $6.0 \mathrm{~Sv}$ (on 20 -h estimates), and the impact of instrumental error is an order of magnitude less than the sampling error.

\section{b. Error in CPIES velocities}

Next, we estimate a theoretical error for absolute velocities and transport derived from CPIES data. Our error analysis largely follows the methods of Meinen and Watts (2000) and Donohue et al. (2010), who consider the worst case scenario by propagating maximum conceivable errors. CPIES error has two independent contributions: the error of the baroclinic (bc) geostrophic velocity and the error of the directly measured barotropic (bt) velocity. Thus, the squared velocity error is

$$
\left\langle(\delta v)^{2}\right\rangle=\left\langle\left(\delta v_{\mathrm{bc}}\right)^{2}\right\rangle+\left\langle\left(\delta v_{\mathrm{bt}}\right)^{2}\right\rangle,
$$

where $\langle$.$\rangle is the expectation or time-averaging operator.$

The barotropic velocity is taken as the average velocity from near-bottom current meter measurements at adjacent CPIES sites, $v_{\mathrm{bt}}=\left(v_{\mathrm{A}}+v_{\mathrm{B}}\right) / 2$; hence, we calculate the barotropic velocity error variance in the same way as above, using Eq. (A3). For the Aanderaa ZPulse instruments on the CPIES, the instrumental error is $0.5 \mathrm{~cm} \mathrm{~s}^{-1}$ and the background variance (on 40-h lowpassed velocity) is $\sigma_{b}=8 \mathrm{~cm} \mathrm{~s}^{-1}$. For pair P2-P3 with a separation distance of $\Delta x=35 \mathrm{~km}$, this gives $\delta v_{\mathrm{bt}}=$ $0.02 \mathrm{~m} \mathrm{~s}^{-1}$. As above, this error is dominated by the sampling error.

The baroclinic velocity error from CPIES is much more complex, although the spatial sampling error is zero, since geostrophy is an integral quantity. There are three main components: instrumental errors related to round-trip travel time index $\tau_{\text {index }}$ and pressure drift, variance in the density field that is not captured by $\tau_{\text {index }}$ and the GEM, and uncertainty in the distance $L$ separating two CPIES.

The baroclinic velocity profile between two CPIES at sites $\mathrm{A}$ and $\mathrm{B}$ is

$$
v_{\mathrm{bc}}(p)=\frac{1}{f L}\left[\Phi_{\mathrm{B}}(p)-\Phi_{\mathrm{A}}(p)\right]
$$

where $f$ is the Coriolis frequency, and $\Phi(p)$ is geopotential anomaly, calculated as

$$
\Phi(p)=\int_{p_{\text {ref }}}^{p} \xi\left(p^{\prime}\right) d p^{\prime},
$$

where $\xi(p)$ is the specific volume anomaly profile, and $p_{\text {ref }}$ is the near-bottom reference pressure of integration. Equation (A7) shows that the error in the baroclinic velocity arises from errors in both CPIES separation and in geopotential anomaly, such that
TABLE A1. Estimated transport errors from current meter moorings (Sv). Errors are calculated without and with instrumental error $\sigma_{r}\left(\mathrm{~cm} \mathrm{~s}^{-1}\right)$. Errors are larger for the second deployment and depend strongly on the depth and separation of mooring pairs.

\begin{tabular}{cccccccc}
\hline $\begin{array}{c}\text { Mooring } \\
\text { pair }\end{array}$ & $\mathrm{AB}$ & $\mathrm{BC}$ & $\mathrm{CD}$ & $\mathrm{DE}$ & $\mathrm{EF}$ & $\mathrm{FG}$ & $\begin{array}{c}\text { Whole } \\
\text { array }\end{array}$ \\
\hline $\begin{array}{c}\text { Deployment } 1 \\
\quad\end{array}$ & & & & & & & \\
$\quad \begin{array}{l}\sigma_{r}=0 \\
\sigma_{r}=0.007\end{array}$ & 0.08 & 0.17 & 1.55 & 2.15 & 1.58 & 2.54 & 5.23 \\
$\begin{array}{c}\text { Deployment 2 } \\
\quad\end{array}$ & 0.11 & 0.24 & 1.64 & 2.23 & 1.68 & 2.64 & 5.49 \\
$\quad$ & & & & & & \\
$\sigma_{r}=0$ & 0.12 & 0.25 & 2.16 & 2.98 & 2.21 & 3.53 & 6.41 \\
$\sigma_{r}=0.009$ & 0.15 & 0.31 & 2.23 & 3.04 & 2.28 & 3.6 & 6.58 \\
\hline
\end{tabular}

$$
\begin{aligned}
\left\langle\left(\delta v_{\mathrm{bc}}\right)^{2}\right\rangle & =2\left\langle\left(\frac{\delta \Phi}{f L}\right)^{2}\right\rangle+\left\langle\left(\frac{v_{\mathrm{bc}} \delta L}{L}\right)^{2}\right\rangle \\
& =\left\langle\left(\delta v_{\mathrm{bc}}\right)_{\Phi}^{2}\right\rangle+\left\langle\left(\delta v_{\mathrm{bc}}\right)_{L}^{2}\right\rangle,
\end{aligned}
$$

where the dependency on $p$ is implicit.

For the separation error, we note that $L=X_{\mathrm{B}}-X_{\mathrm{A}}$ where $X$ is the position of the CPIES along the array, and $b$ is a bias error in this position. Thus, the separation distance error $\delta L$ is $\left\langle(\delta L)^{2}\right\rangle=2 b^{2}$. CPIES P2, P3, and P4 were surveyed, giving positions with accuracy better than $250 \mathrm{~m}$. However, there was no surveyed position for P5, so we take $b=1 \mathrm{~km}$ as a worst case scenario, resulting in $\left(\delta v_{\mathrm{bc}}\right)_{L}=0.009 \mathrm{~m} \mathrm{~s}^{-1}$ at the surface.

The component of the baroclinic velocity error from the geopotential anomaly error $\left(\delta v_{\mathrm{bc}}\right)_{\Phi}$ has itself two sources of error. The first $(\delta \Phi)_{\mathrm{GEM}}$ arises from the inability of the GEM to capture the full hydrographic variability observed in the region. The second $(\delta \Phi)_{\tau}$ is largely a combination of instrument and sampling errors. These two errors are independent, so that the total mean square error of the geopotential anomaly is given by

$$
\left\langle(\delta \Phi)^{2}\right\rangle=\left\langle(\delta \Phi)_{\mathrm{GEM}}^{2}\right\rangle+\left\langle(\delta \Phi)_{\tau}^{2}\right\rangle .
$$

The error from the GEM is propagated from the specific volume anomaly $\xi$ of (A8), assuming that errors are independent between all fixed pressure levels:

$$
\left\langle(\delta \Phi)_{\mathrm{GEM}}^{2}\right\rangle=\sum_{p=p_{\mathrm{ref}}}^{p}\left[\delta \xi(p) \Delta p^{\prime}(p)\right]^{2},
$$

where $\Delta p^{\prime}(p)$ is the varying pressure increment of the GEM field. We define the error in specific volume anomaly $\delta \xi$ as the rms error at each pressure level, across all travel times, between observed $\xi$ (from all hydrographic casts) and the GEM, which is a spline fit to $\xi$ at each pressure level. Figure 4 shows the GEM field and $\delta \xi$ as a function of pressure. We find that the error variance $(\delta \Phi)_{\mathrm{GEM}}$ translates to a baroclinic velocity error of less 
than $0.06 \mathrm{~m} \mathrm{~s}^{-1}$ below $200-\mathrm{m}$ depth, with a maximum error of $0.11 \mathrm{~m} \mathrm{~s}^{-1}$ at the surface.

The size of $(\delta \Phi)_{\tau}$ can also be deduced from the GEM (Donohue et al. 2010):

$$
\delta \Phi_{\tau}=\delta \tau_{\text {index }} \frac{\partial \Phi}{\partial \tau_{\text {index }}},
$$

where $\delta \tau_{\text {index }}$ is the error in acoustic round-trip travel time, referenced to $1900 \mathrm{db}$ in the Agulhas. The gradient $\partial \Phi / \partial \tau_{\text {index }}$ is a function of both pressure and $\tau_{\text {index }}$ itself, so to simplify we evaluate it only for the modal value (averaged across all CPIES) of $\tau_{\text {index }}$. To estimate $\delta \tau_{\text {index }}$, we need to consider how $\tau_{\text {index }}$ is calculated (Donohue et al. 2010):

$$
\tau_{\text {index }}=A \tau_{\text {dyn }}^{2}+B \tau_{\text {dyn }}+C, \quad \text { or } \quad \tau_{\text {index }}=A \tau_{\text {dyn }}+B,
$$

depending on if the relationship between $\tau_{\mathrm{dyn}}$ and $\tau_{\text {index }}$ is chosen as a linear or quadratic fit to the observations, and

$$
\tau_{\mathrm{dyn}}=F\left(\tau_{\mathrm{CPIES}}-\tau_{B}\right)-\tau_{S}-\tau_{\mathrm{OFFSET}},
$$

where $\tau_{\text {CPIES }}$ is the hourly travel time measured directly by the CPIES; $\tau_{B}$ is the correction for mass loading that includes the tides; $F$ is the conversion coefficient from the baroclinic travel time to the dynamic travel time $\tau_{\text {dyn }}$ (Watts et al. 2001); $\tau_{S}$ is the correction for seasonality of the data; and $\tau_{\text {OFFSET }}$ is the offset to go from the pressure level of each individual CPIES instrument to the uniform pressure level of reference, chosen as $3800 \mathrm{dbar}$ for the ACT array.

We use the quadratic fit in Eq. (A13) for processing the CPIES data, but we note that the residuals between the observations and a linear fit are larger, and so we conservatively use that error $(0.48 \mathrm{~ms}$ for the linear fit and $0.47 \mathrm{~ms}$ for the quadratic fit). For the ACT data, $1-$ $F<5 \times 10^{-4}$, so we take $F \approx 1$. Thus, the travel time error becomes

$$
\begin{aligned}
\left\langle\left(\delta \tau_{\text {index }}\right)^{2}\right\rangle= & \left\langle\left(\delta \tau_{\text {CPIES }}\right)^{2}\right\rangle+\left\langle\left(\delta \tau_{B}\right)^{2}\right\rangle+\left\langle\left(\delta \tau_{S}\right)^{2}\right\rangle \\
& +\left\langle\left(\delta \tau_{\text {OFFSET }}\right)^{2}\right\rangle+\left\langle\left(\delta \tau_{\text {FIT }}\right)^{2}\right\rangle
\end{aligned}
$$

Donohue et al. (2010) noted that further errors can be because of the spatial offset between the calibration hydrocast and CPIES, internal tides, deep density variability, and error in the $\tau_{\text {dyn }}$ calculation. However, we expect these errors to be smaller than any of those explicit in Eq. (A15).
We now consider the errors in each term of Eq. (A15). Each hourly ensemble of $24 \tau_{\text {CPIES }}$ pings has a typical standard deviation of $2.2 \mathrm{~ms}$ (Kennelly et al. 2007), reducing to $\delta \tau_{\text {CPIES }}=(2.2 \mathrm{~ms})(24 \times 20)^{-1 / 2}=0.1 \mathrm{~ms}$ for 40-h low-passed data. The term $\delta \tau_{B}$ has two contributions: the residual from the tidal correction $\delta \tau_{\mathrm{TIDE}}$ and the pressure sensor drift $\delta \tau_{\text {LOAD }}$. The quantity $\delta \tau_{\text {TIDE }}$ is taken as the difference between two tidal estimates: a least squares fit to 97 tidal constituents as applied here and the response method of Munk and Cartwright (1966). This rms difference averaged across all CPIES sites is 1 mbar, which translates to a travel time error of $\delta \tau_{\mathrm{TIDE}}=0.02 \mathrm{~ms}$. For $\delta \tau_{\mathrm{LOAD}}$, we consider the worst case scenario that our drift correction is attributable to a real oceanic trend and hence translates into an error. The average instrument drift is $8 \mathrm{mbar}$, which translates to a travel time error of $\delta \tau_{\mathrm{LOAD}}=0.05 \mathrm{~ms}$. Hence, $\delta \tau_{B}=\sqrt{\delta \tau_{\mathrm{LOAD}}^{2}+\delta \tau_{\mathrm{TIDE}}^{2}} \approx 0.05 \mathrm{~ms}$.

In the CPIES processing, a seasonal correction $\tau_{S}$ is modeled as a sinusoidal function with annual period. The amplitude and phase of this function are from a least squares fit to travel time over the top $200 \mathrm{dbar}$, calculated from the hydrographic data that go into the GEM. The rms of the residuals of this fit is taken as the error in the seasonal correction, that is, $\delta \tau_{S}=0.5 \mathrm{~ms}$. This error is actually larger than the amplitude of the seasonal cycle, estimated at $0.42 \mathrm{~ms}$. Levelling the CPIES introduces another error $\delta \tau_{\text {OFFSET }}$ (Donohue et al. 2010). The maximum scatter in $\tau_{\text {OFFSET }}$ occurs at $\mathrm{P} 4$ based on five hydrographic casts $(0.43 \mathrm{~ms}$ for the standard error of the mean), and the minimum occurs at P6 based on only two casts $(0.12 \mathrm{~ms})$. We take the maximum $\delta \tau_{\mathrm{OFFSET}}=0.43 \mathrm{~ms}$. The sum of all these travel time errors [using Eq. (A15)] results in $\delta \tau_{\text {index }}=1.15 \mathrm{~ms}$ in the Agulhas region. For comparison, Donohue et al. (2010) obtained an error of $1.02 \mathrm{~ms}$ for a travel time index at 1400 dbar in the Kuroshio region. Using Eqs. (A9), (A10), and (A12), assuming the GEM error $(\delta \Phi)_{\mathrm{GEM}}=0$, the travel time error translates to a baroclinic velocity error profile that steadily decreases from $0.20 \mathrm{~m} \mathrm{~s}^{-1}$ at the surface to $0.02 \mathrm{~m} \mathrm{~s}^{-1}$ at $2000 \mathrm{~m}$ and down to zero at the seabed. Hence, at the surface the contribution from the travel time error is twice as large as that from the GEM.

All together these errors from the CPIES translate to a profile of baroclinic velocity error from geopotential anomaly $\left(\delta v_{\mathrm{bc}}\right)_{\Phi}$ with values of the order $0.01 \mathrm{~m} \mathrm{~s}^{-1}$ at $4000 \mathrm{dbar}$, increasing monotonically to $0.1 \mathrm{~m} \mathrm{~s}^{-1}$ at $1000 \mathrm{dbar}$ and to a maximum $0.23 \mathrm{~m} \mathrm{~s}^{-1}$ at the surface. The total CPIES velocity error $\delta v(z)$ for CPIES pair P2$\mathrm{P} 3$ is plotted in Fig. 5e and compared to the observed (root-mean-square) difference between CPIES and CM velocities at mooring $\mathrm{G}$. 
Finally, we estimate the total CPIES-derived transport error. For the baroclinic component, we vertically integrate the velocity error profile derived above and multiply by the separation distance $L$ between each CPIES pair. For the barotropic component we use Eq. (A5). Note that the baroclinic (geostrophic) error [Eq. (A9)] is independent of $L$, but the barotropic error is not and grows significantly owing to the large separation distance between CPIES. The total transport error, across both P3-P4 and P4-P5 as used in our Agulhas Current transport calculation, is then $10.3 \mathrm{~Sv}$ for baroclinic and $8.8 \mathrm{~Sv}$ for barotropic, yielding a total estimated error on CPIES transport of $13.5 \mathrm{~Sv}$ at each 20 -h time step. Based on the comparison of overlapping transports from CPIES pair P3-P4 and mooring G (Table 2), these errors are $30 \%$ larger than those observed, suggesting a substantial overestimate of the actual CPIES error.

\section{c. Total transport error}

For an estimate of the total error on Agulhas Current transport, we combine the CPIES and CM errors derived above, assuming they are independent (Table 3). In the case of $T_{\text {box }}, \mathrm{CM}$ errors alone represent the best error estimate since the limit of integration is fixed at $220 \mathrm{~km}$, approximately at the end of the CM array. For the mean transports, $\mathrm{CM}$ errors reduce dramatically $(0.5 \mathrm{~Sv})$, while CPIES errors do not $(9.0 \mathrm{~Sv})$ because most CPIES errors are not random. Only component $\delta \tau_{\text {CPIES }}$ reduces with number of samples, and the seasonal error $\tau_{s}$ cancels when averaged over approximately an integer number of years.

\section{REFERENCES}

Anderson, D. L., and R. A. Corry, 1985: Seasonal transport variations in the Florida Straits: A model study. J. Phys. Oceanogr., 15, 773-786, doi:10.1175/1520-0485(1985)015<0773: STVITF $>2.0 . \mathrm{CO} ; 2$.

Barlow, R., T. Lamont, M. Kyewalyanga, H. Sessions, and T. Morris, 2010: Phytoplankton production and physiological adaptation on the southeastern shelf of the Agulhas ecosystem. Cont. Shelf Res., 30, 1472-1486, doi:10.1016/j.csr.2010.05.007.

Beal, L. M., 2009: A time series of Agulhas Undercurrent transport. J. Phys. Oceanogr., 39, 2436-2450, doi:10.1175/2009JPO4195.1.

— dercurrent. Deep-Sea Res., 44, 1715-1724, doi:10.1016/ S0967-0637(97)00033-2.

, and - 1999: The velocity and vorticity structure of the Agulhas Current at $32^{\circ}$ S. J. Geophys. Res., 104, 5151-5176, doi:10.1029/1998JC900056.

-, T. K. Chereskin, Y. D. Lenn, and S. Elipot, 2006: The sources and mixing characteristics of the Agulhas Current. J. Phys. Oceanogr., 36, 2060-2074, doi:10.1175/ JPO2964.1.

- , and Coauthors, 2011: On the role of the Agulhas system in ocean circulation and climate. Nature, 472, 429-436, doi:10.1038/ nature09983.
Biastoch, A., and C. W. Böning, 2013: Anthropogenic impact on Agulhas leakage. Geophys. Res. Lett., 40, 1138-1143, doi:10.1002/grl.50243.

— C. Reason, J. Lutjeharms, and O. Boebel, 1999: The importance of flow in the Mozambique Channel to seasonality in the greater Agulhas Current system. Geophys. Res. Lett., 26, 3321-3324, doi:10.1029/1999GL002349.

— C. W. Böning, F. Schwarzkopf, and J. Lutjeharms, 2009: Increase in Agulhas leakage due to poleward shift of Southern Hemisphere westerlies. Nature, 462, 495-498, doi:10.1038/ nature08519.

Bretherton, F. P., R. E. Davis, and C. Fandry, 1976: A technique for objective analysis and design of oceanographic experiments applied to MODE-73. Deep-Sea Res. Oceanogr. Abstr., 23, 559-582, doi:10.1016/0011-7471(76)90001-2.

Bryden, H. L., L. M. Beal, and L. M. Duncan, 2005: Structure and transport of the Agulhas Current and its temporal variability. J. Oceanogr., 61, 479-492, doi:10.1007/s10872-005-0057-8.

Casal, T. G., L. M. Beal, R. Lumpkin, and W. E. Johns, 2009: Structure and downstream evolution of the Agulhas Current system during a quasi-synoptic survey in FebruaryMarch 2003. J. Geophys. Res., 114, C03001, doi:10.1029/ 2008JC004954.

Cessi, P., 1990: Recirculation and separation of boundary currents. J. Mar. Res., 48, 1-35, doi:10.1357/002224090784984597.

Czeschel, L., C. Eden, and R. J. Greatbatch, 2012: On the driving mechanism of the annual cycle of the Florida Current transport. J. Phys. Oceanogr., 42, 824-839, doi:10.1175/ JPO-D-11-0109.1.

Daley, R., 1991: Atmospheric Data Analysis. Cambridge University Press, $457 \mathrm{pp}$.

De Ruijter, W. P., H. Ridderinkhof, and M. W. Schouten, 2005 : Variability of the southwest Indian Ocean. Philos. Trans. Roy. Soc. London, A363, 63-76, doi:10.1098/rsta.2004.1478.

Donohue, K. A., D. R. Watts, K. L. Tracey, A. D. Greene, and M. Kennelly, 2010: Mapping circulation in the Kuroshio Extension with an array of current and pressure recording inverted echo sounders. J. Atmos. Oceanic Technol., 27, 507527, doi:10.1175/2009JTECHO686.1.

Fan, J., and I. Gijbels, 1996: Local Polynomial Modelling and its Applications. Monogr. Stat. Appl. Probab., Vol. 66, CRC Press, $360 \mathrm{pp}$.

Fandry, C., and R. D. Pillsbury, 1979: On the estimation of absolute geostrophic volume transport applied to the Antarctic Circumpolar Current. J. Phys. Oceanogr., 9, 449-455, doi:10.1175/ 1520-0485(1979)009<0449:OTEOAG > 2.0.CO;2.

Ganachaud, A., and C. Wunsch, 2000: Improved estimates of global ocean circulation, heat transport and mixing from hydrographic data. Nature, 408, 453-457, doi:10.1038/ 35044048 .

Gill, A., and E. Schumann, 1979: Topographically induced changes in the structure of an inertial coastal jet: Application to the Agulhas Current. J. Phys. Oceanogr., 9, 975-991, doi:10.1175/ 1520-0485(1979)009<0975:TICITS > 2.0.CO;2.

Gille, S. T., 2003: Float observations of the Southern Ocean. Part II: Eddy fluxes. J. Phys. Oceanogr., 33, 1182-1196, doi:10.1175/ 1520-0485(2003)033<1182:FOOTSO > 2.0.CO;2.

Gordon, A. L., 1986: Interocean exchange of thermocline water. J. Geophys. Res., 91, 5037-5046, doi:10.1029/ JC091iC04p05037.

_ 2004-2006 as observed by the INSTANT program. Dyn. Atmos. Oceans, 50, 115-128, doi:10.1016/j.dynatmoce.2009.12.002. 
Halkin, D., and T. Rossby, 1985: The structure and transport of the Gulf Stream at $73^{\circ}$ W. J. Phys. Oceanogr., 15, 1439-1452, doi:10.1175/1520-0485(1985)015<1439:TSATOT>2.0.CO;2.

Hogg, N. G., and W. E. Johns, 1995: Western boundary currents. Rev. Geophys., 33, 1311-1334, doi:10.1029/95RG00491.

- , and D. E. Frye, 2007: Performance of a new generation of acoustic current meters. J. Phys. Oceanogr., 37, 148-161, doi:10.1175/JPO3003.1.

Holland, W. R., and P. B. Rhines, 1980: An example of eddyinduced ocean circulation. J. Phys. Oceanogr., 10, 1010-1031, doi:10.1175/1520-0485(1980)010<1010:AEOEIO>2.0.CO;2.

Johns, W., T. Kanzow, and R. Zantopp, 2005: Estimating ocean transports with dynamic height moorings: An application in the Atlantic deep western boundary current at $26^{\circ} \mathrm{N}$. Deep-Sea Res., 52, 1542-1567, doi:10.1016/j.dsr.2005.02.002.

Jury, M. R., H. R. Valentine, and J. R. Lutjeharms, 1993: Influence of the Agulhas Current on summer rainfall along the southeast coast of South Africa. J. Appl. Meteor., 32, 1282-1287, doi:10.1175/1520-0450(1993)032<1282:IOTACO >2.0.CO;2.

Kanzow, T., and Coauthors, 2010: Seasonal variability of the Atlantic meridional overturning circulation at $26.5^{\circ} \mathrm{N}$. J. Climate, 23, 5678-5698, doi:10.1175/2010JCLI3389.1.

Kennelly, M., K. L. Tracey, and D. R. Watts, 2007: Inverted echo sounder data processing manual. University of Rhode Island GSO Tech. Rep. 2007-02, 89 pp. [Available online at www.po.gso.uri.edu/dynamics/publications/ tech_rpts/IESprocessman.pdf.]

Krug, M., and J. Tournadre, 2012: Satellite observations of an annual cycle in the Agulhas Current. Geophys. Res. Lett., 39, L15607, doi:10.1029/2012GL052335.

$\_, \ldots$, and F. Dufois, 2014: Interactions between the Agulhas Current and the eastern margin of the Agulhas Bank. Cont. Shelf Res., 81, 67-79, doi:10.1016/j.csr.2014.02.020.

Le Bars, D., H. A. Dijkstra, and W. P. M. De Ruijter, 2013: Impact of the Indonesian Throughflow on Agulhas leakage. Ocean Sci., 9, 773-785, doi:10.5194/os-9-773-2013.

Leber, G. M., and L. M. Beal, 2014: Evidence that Agulhas Current transport is maintained during a meander. J. Geophys. Res. Oceans, 119, 3806-3817, doi:10.1002/2014JC009802.

Lee, T., and Coauthors, 2010: Consistency and fidelity of Indonesian-Throughflow total volume transport estimated by 14 ocean data assimilation products. Dyn. Atmos. Oceans, 50, 201-223, doi:10.1016/j.dynatmoce.2009.12.004.

Loveday, B. R., J. V. Durgadoo, C. J. Reason, A. Biastoch, and P. Penven, 2014: Decoupling of the Agulhas leakage from the Agulhas Current. J. Phys. Oceanogr., 44, 1776-1797, doi:10.1175/JPO-D-13-093.1.

Lumpkin, R., and K. Speer, 2007: Global ocean meridional overturning. J. Phys. Oceanogr., 37, 2550-2562, doi:10.1175/JPO3130.1.

Lutjeharms, J., and H. Roberts, 1988: The Natal pulse: An extreme transient on the Agulhas Current. J. Geophys. Res., 93, 631645, doi:10.1029/JC093iC01p00631.

Matano, R., E. Beier, P. Strub, and R. Tokmakian, 2002: Largescale forcing of the Agulhas variability: The seasonal cycle. J. Phys. Oceanogr., 32, 1228-1241, doi:10.1175/1520-0485(2002)032<1228: LSFOTA $>2.0 . \mathrm{CO} ; 2$.

$\longrightarrow, \ldots$, and — 2008: The seasonal variability of the circulation in the south Indian Ocean: Model and observations. J. Mar. Syst., 74, 315-328, doi:10.1016/j.jmarsys.2008.01.007.

Meinen, C. S., and D. R. Watts, 2000: Vertical structure and transport on a transect across the North Atlantic Current near $42^{\circ} \mathrm{N}$ : Time series and mean. J. Geophys. Res., 105, 21869 21 891, doi:10.1029/2000JC900097.
Munk, W. H., 1950: On the wind-driven ocean circulation. J. Meteor., 7, 80-93, doi:10.1175/1520-0469(1950)007<0080: OTWDOC $>2.0 . \mathrm{CO} ; 2$.

- , and D. E. Cartwright, 1966: Tidal spectroscopy and prediction. Philos. Trans. Roy. Soc. London, A259, 533-581, doi:10.1098/rsta.1966.0024.

Nelder, J. A., and R. Mead, 1965: A simplex method for function minimization. Comput. J., 7, 308-313, doi:10.1093/ comjnl/7.4.308.

Pearce, A., and M. Grundlingh, 1982: Is there a seasonal variation in the Agulhas Current? J. Mar. Res., 40, 177-184.

Peeters, F. J., R. Acheson, G.-J. A. Brummer, W. P. De Ruijter, R. R. Schneider, G. M. Ganssen, E. Ufkes, and D. Kroon, 2004: Vigorous exchange between the Indian and Atlantic Oceans at the end of the past five glacial periods. Nature, 430, 661-665, doi:10.1038/nature02785.

Percival, D. B., and A. T. Walden, 1993: Spectral Analysis for Physical Applications. Cambridge University Press, 583 pp.

Rahmstorf, S., 1996: On the freshwater forcing and transport of the Atlantic thermohaline circulation. Climate Dyn., 12, 799-811, doi:10.1007/s003820050144.

Reason, C., 2001: Evidence for the influence of the Agulhas Current on regional atmospheric circulation patterns. J. Climate, 14, 2769-2778, doi:10.1175/1520-0442(2001)014<2769: EFTIOT $>2.0 . \mathrm{CO} ; 2$.

Ridderinkhof, H., P. Van der Werf, J. Ullgren, H. Van Aken, P. van Leeuwen, and W. De Ruijter, 2010: Seasonal and interannual variability in the Mozambique Channel from moored current observations. J. Geophys. Res., 115, C06010, doi:10.1029/ 2009JC005619.

Rossby, T., C. Flagg, and K. Donohue, 2010: On the variability of Gulf Stream transport from seasonal to decadal timescales. J. Mar. Res., 68, 503-522, doi:10.1357/002224010794657128.

Rouault, M., S. White, C. Reason, J. Lutjeharms, and I. Jobard, 2002: Ocean-atmosphere interaction in the Agulhas Current region and a South African extreme weather event. Wea. Forecasting, 17, 655-669, doi:10.1175/1520-0434(2002)017<0655: OAIITA $>2.0 . \mathrm{CO} ; 2$.

- , P. Penven, and B. Pohl, 2009: Warming in the Agulhas Current system since the 1980's. Geophys. Res. Lett., 36, L12602, doi:10.1029/2009GL037987.

Sato, O. T., and T. Rossby, 1995: Seasonal and low frequency variations in dynamic height anomaly and transport of the Gulf Stream. Deep-Sea Res., 42, 149-164, doi:10.1016/ 0967-0637(94)00034-P.

Schouten, M. W., W. P. de Ruijter, and P. J. van Leeuwen, 2002: Upstream control of Agulhas ring shedding. J. Geophys. Res., 107, doi:10.1029/2001JC000804.

Schumann, E., and K. Brink, 1990: Coastal-trapped waves off the coast of South Africa: Generation, propagation, and current structures. J. Phys. Oceanogr., 20, 1206-1218, doi:10.1175/ 1520-0485(1990)020<1206:CTWOTC $>2.0 . C O ; 2$

Shen, M.-L., Y.-H. Tseng, S. Jan, C.-C. Young, and M.-D. Chiou, 2014: Long-term variability of the Kuroshio transport east of Taiwan and the climate it conveys. Prog. Oceanogr., 121, 60 73, doi:10.1016/j.pocean.2013.10.009.

Silverman, B. W., 1986: Density Estimation for Statistics and Data Analysis. Chapman and Hall, 176 pp.

van Leeuwen, P. J., W. P. Ruijter, and J. R. Lutjeharms, 2000: Natal pulses and the formation of Agulhas rings. J. Geophys. Res., 105, 6425-6436, doi:10.1029/1999JC900196.

Vignudelli, S., A. G. Kostianoy, P. Cipollini, and J. Benveniste, 2011: Coastal Altimetry. Springer, 565 pp. 
Watts, D. R., and H. Kontoyiannis, 1990: Deep-ocean bottom pressure measurement: Drift removal and performance. J. Atmos. Oceanic Technol., 7, 296-306, doi:10.1175/1520-0426(1990)007<0296: DOBPMD $>2.0 . \mathrm{CO} ; 2$.

C. Sun, and S. Rintoul, 2001: A two-dimensional gravest empirical mode determined from hydrographic observations in the subantarctic front. J. Phys. Oceanogr., 31, 2186-2209, doi:10.1175/ 1520-0485(2001)031<2186:ATDGEM>2.0.CO;2.
Weijer, W., W. P. De Ruijter, A. Sterl, and S. S. Drijfhout, 2002: Response of the Atlantic overturning circulation to South Atlantic sources of buoyancy. Global Planet. Change, 34, 293311, doi:10.1016/S0921-8181(02)00121-2.

Xie, S.-P., H. Annamalai, F. A. Schott, and J. P. McCreary Jr., 2002: Structure and mechanisms of south Indian Ocean climate variability. J. Climate, 15, 864-878, doi:10.1175/ 1520-0442(2002)015<0864:SAMOSI >2.0.CO;2. 